NBER WORKING PAPER SERIES

\title{
MONETARY POLICY, ASSET-PRICE BUBBLE AND THE ZERO LOWER BOUND
}

\author{
Tim Robinson \\ Andrew Stone \\ Working Paper 11105 \\ http://www.nber.org/papers/w11105
}

\author{
NATIONAL BUREAU OF ECONOMIC RESEARCH \\ 1050 Massachusetts Avenue \\ Cambridge, MA 02138 \\ February 2005
}

We are grateful to LouiseWilkinson for coding assistance, and to colleagues at the Reserve Bank, as well as Piti Disyatat, Kenneth Kuttner, Andrew Rose, Takatoshi Ito and other participants at the 15th Annual East Asian Seminar on Economics, for helpful comments. The views expressed in this paper are those of the authors and should not be attributed to the Reserve Bank of Australia or the National Bureau of Economic Research.

(C) 2005 by Tim Robinson and Andrew Stone. All rights reserved. Short sections of text, not to exceed two paragraphs, may be quoted without explicit permission provided that full credit, including $\odot$ notice, is given to the source. 
Monetary Policy, Assset-Price Bubbles and the Zero Lower Bound

Tim Robinson and Andrew Stone

NBER Working Paper No. 11105

February 2005

JEL No. E32, E52, E60

\section{ABSTRACT}

We use a simple model of a closed economy to study the recommendations of monetary policymakers, attempting to respond optimally to an asset-price bubble whose stochastic properties they understand. We focus on the impact which the zero lower bound (ZLB) on nominal interest rates has on the recommendations of such policy-makers. For a given target inflation rate, we identify several different forms of 'insurance' which policy-makers could potentially take out against encountering the ZLB due to the future bursting of a bubble. Even with perfect knowledge of the bubble process, however, which of these will be optimal varies from one type of bubble to another and, for certain bubbles, from one period to the next. It is therefore difficult to say whether the ZLB should cause policy-makers to operate policy more tightly or loosely than they would otherwise do, while a bubble is growing - even after abstracting from the informational difficulties they face in practice. We also examine the implications of the ZLB for policy-makers' preferences as to their inflation target. Policy-makers who wish to avoid concerns about the ZLB should take care not to set too low a target - especially if the neutral real interest rate is low.

Tim Robinson

Overseas Economies Section

Economic Group

Reserve Bank of Australia

GPO Box 3947

Sydney, New South Wales

Australia 2001
Andrew Stone

Economic Research Department

Economic Group

Reserve Bank of Australia

GPO Box 3947

Sydney, New South Wales

Australia 2001 


\section{Table of Contents}

$\begin{array}{ll}\text { 1. Introduction } & 1\end{array}$

2. Methodology 3

2.1 The augmented Ball-Svensson Model 3

$\begin{array}{lll}2.2 & \text { Activist and sceptical policy-makers } & 7\end{array}$

3. How Might the Zero Lower Bound Influence an Activist Policymaker? 9

3.1 The case of bubbles whose development is exogenous 10

3.2 The case of bubbles whose development is affected by policy 14

3.3 An insurance interpretation for the implications of the ZLB 15

4. Results 16

4.1 Baseline Results: The Case of Exogenous Bubbles 17

4.2 Exogenous Bubbles with Different Probabilities of Bursting 19

4.3 Bubbles whose Growth is Affected by Policy 22

4.4 Bubbles whose Probability of Bursting is Affected by Policy 26

4.5 Sensitivity to Model Parameters 29

5. Conclusions 32

Appendix A: Recent Literature 36

Appendix B: The Phase Diagram for the Ball-Svensson Model under Optimal Policy

Appendix C: The Case of Rational Bubbles

References 


\title{
MONETARY POLICY, ASSET-PRICE BUBBLES AND THE ZERO LOWER BOUND
}

\author{
Tim Robinson and Andrew Stone
}

\section{Introduction}

In a low inflation economy, the bursting of an asset-price bubble can have significant and long-lasting consequences, both for the economy and for the operation of monetary policy. In Japan, the collapse of a major bubble in property and stock prices in the early 1990s ushered in over a decade of weak growth and declining price pressures - culminating, by late 1998, in ongoing consumer price deflation. This, in turn, has seen the Bank of Japan constrained in its actions, for over five years, by the zero lower bound (ZLB) on nominal interest rates. Likewise, the tech stock crash in the US in 2000 marked the start of an economic downturn which saw the year-ended growth rate of the personal consumption expenditure price index decline briefly to below 1 per cent, and prompted concerns for a time that the US federal funds rate might also reach the zero lower bound.

These examples suggest, at the very least, that the interaction between asset-price bubbles and monetary policy is an important one for policy-makers, especially if operating in a low inflation environment. If asset-price bubble collapses represent a primary mechanism by which otherwise well-functioning economies may become seriously destabilised, even to the point where monetary policy becomes constrained by the ZLB, this raises key questions for policy-makers as to how they might be able to forestall, or at least reduce, the fall-out from such collapses. These questions relate not just to how policy-makers might wish to react pre-emptively, as asset-price misalignments develop, but also to choices about the framework within which policy is set.

This paper uses a simple, stylised two-equation model, due originally to Ball (1999a) and Svensson (1997), to explore these questions. More precisely, it builds upon recent work by Gruen, Plumb and Stone (2003), in which the Ball-Svensson model was augmented by the inclusion of an asset-price bubble. Gruen et al then used this augmented model to investigate the implications of such bubbles for optimal policy settings, under a variety of assumptions both about the 
bubble's stochastic behaviour, and about the degree to which this behaviour can be influenced by the actions of policy-makers.

Gruen et al (2003) highlighted two conflicting influences on policy-makers, attempting to handle a developing bubble. On the one hand, they are likely to become more confident as time passes that observed asset-price rises do indeed constitute a bubble, and so become more willing to respond actively to these rises. At the same time, however, they would become increasingly conscious of the negative effects on the economy from the bubble's eventual bursting - effects which they would be anxious not to compound, given the delay with which any ex-post monetary loosening would flow through to real activity.

As a result of these competing influences, Gruen et al (2003) found that, even with perfect knowledge both of the economy and of the parameters governing a bubble's stochastic behaviour, it may be unclear whether policy-makers would wish to tighten policy in the face of such a bubble, beyond the degree to which they would do so based on an efficient markets view of asset prices. Their results highlighted the stringent information requirements therefore inherent in a pre-emptive policy approach to asset-price bubbles - and the need for delicate judgements, in pursuing such a strategy, about both the process driving the bubble and its likely sensitivity to monetary policy.

In this paper we extend the work of Gruen et al by removing one simplification built into their modelling approach. This was the assumption that, whenever the economy is struck by a large negative shock, such as the bursting of an asset-price bubble, policy-makers can set the real interest rate as far below neutral as desired, regardless of the current level of inflation. This is equivalent to assuming that, at all times, the nominal interest rate may be set arbitrarily, so ignoring the ZLB.

By contrast, in this paper we impose a zero lower bound on nominal interest rates, as a constraint on the actions of policy-makers attempting to deal with a developing asset-price bubble. We then examine the implications this has both: for the behaviour of policy-makers who believe that they understand the stochastic properties of the bubble; and for the policy framework within which they must make their decisions.

With regard to the former, policy-makers who wish to react pre-emptively to a growing bubble must now take into account whether their current actions might 
result in them being unable to set the real interest rate optimally in subsequent periods, whenever the bubble bursts. Moreover, in doing so, they must allow for the possibility not merely that their actions might become constrained in the period in which the bubble actually bursts, but also that this might occur with a lag (as the bubble's collapse flows through to lower inflation, so reducing the amount by which the real interest rate can be set below neutral). ${ }^{1}$

As regards the latter issue, with a zero lower bound on nominal interest rates the level of inflation immediately prior to an asset-price bubble collapse clearly becomes important. Hence, this constraint may influence decisions about aspects of the policy framework itself, such as policy-makers' preferred choice of target inflation rate.

\section{Methodology}

\subsection{The augmented Ball-Svensson Model}

The starting point for our analysis is a simple model of a closed economy, due to Ball (1999a) and Svensson (1997). This model is described by 2 equations:

$$
\begin{aligned}
& y_{t}=-\beta r_{t-1}+\lambda y_{t-1} \\
& \pi_{t}=\pi_{t-1}+\alpha y_{t-1}
\end{aligned}
$$

where $y$ is the output gap, $r$ is the difference between the real interest rate and its neutral level, $\pi$ is the difference between consumer-price inflation and its targeted rate, and $\alpha, \beta$, and $\lambda$ are positive constants (with $\lambda \leq 1$ so that output gaps do not behave explosively with real interest rates at neutral).

As noted in Gruen et al (2003), the Ball-Svensson model 'has the advantage of simplicity and intuitive appeal. ... It assumes, realistically, that monetary policy

1 Note that our focus in this paper is on the effect which these possibilities (i.e. the presence of the ZLB) might have on the interest rate recommendations of policy-makers, over and above whatever direct impact the presence of the bubble itself might have on these recommendations in the absence of the ZLB. Note also that our focus on the impact of the ZLB on policy-makers' thinking while a bubble is still growing is in contrast to much of the recent research on the ZLB, which has focussed on how policy-makers should react once the ZLB has been reached. A brief review of where this paper sits within the recent literature on both asset-price bubbles and the ZLB is provided in Appendix A. 
affects real output, and hence the output gap, with a lag, and that the output gap affects inflation with a further lag'. We adopt the same baseline values for the parameters $\alpha, \beta$, and $\lambda$ as those chosen by Ball, for the case where each period in the model corresponds to one year, namely $\alpha=0.4, \beta=1$ and $\lambda=0.8 .^{2}$

Next, following Gruen et al (2003), we augment the model with an asset-price bubble. ${ }^{3}$ We assume that in year 0 , the economy is in equilibrium, with both output and inflation at their target values, $y_{0}=\pi_{0}=0$, and that the bubble has zero size, $a_{0}=0$. In subsequent years, we assume that the bubble evolves as follows:

$$
a_{t}= \begin{cases}a_{t-1}+\gamma_{t} & , \text { with probability } 1-p_{t} \\ 0 & , \text { with probability } p_{t}\end{cases}
$$

Thus, in each year, the bubble either grows by an amount, $\gamma_{t}>0$, or bursts and collapses back to zero. We also assume that, once the bubble has burst, it does not re-form. To allow for the effect of the bubble on the economy, we modify the Ball-Svensson model to read:

$$
\begin{aligned}
& y_{t}=-\beta r_{t-1}+\lambda y_{t-1}+\Delta a_{t} \\
& \pi_{t}=\pi_{t-1}+\alpha y_{t-1} .
\end{aligned}
$$

In each year that the bubble is growing it has an expansionary effect on the economy, increasing the level of output, and the output gap, by $\gamma_{t}$. The bubble is, however, assumed to have no direct effect on consumer-price inflation, although there will be consequences for inflation to the extent that the bubble leads the

2 Note that these parameter values were actually calibrated by Ball to fit the US economy, based on previous studies by himself (Ball 1994), DeLong and Summers (1988) and Rudebusch (1995). Ball (1999b) also subsequently took these same base parameter values for use in an open-economy version of the model which he noted was 'meant to apply to medium-to-small open economies such as Canada, Australia and New Zealand' (although an increase in the real interest rate, for example, affects output through two channels in this open economy model - directly and via the exchange rate - rather than just via the former channel). Finally, Ball and Svensson also added white-noise shocks to each of their equations, which we have suppressed for simplicity.

3 The discussion of Equations (3), (4) and (5) below directly mimics that of Gruen et al (2003) initially, but is augmented with a discussion of the rationale for some of the notable features of these equations, such as the absence of any forward-looking component to the inflation expectations formation process embodied in Equation (5). 
economy to operate with excess demand as it expands, and with excess supply when it bursts. When the bubble bursts, the effect on the economy is, of course, contractionary: if the bubble bursts in year $t$, the direct effect on output, and the output gap, in that year will be $\Delta a_{t}=-\sum_{1}^{t-1} \gamma_{t}$. Thus, the longer the bubble survives, the greater will be the contractionary effect on the economy when it bursts.

Equations (3), (4) and (5) describe the model used by Gruen et al (2003), and adopted again here. In a moment we shall want to also incorporate a ZLB on the nominal interest rate into the model, but before doing so it is worth remarking on a number of aspects of the model so far.

The most notable feature of Equations (3), (4) and (5) is that the treatment of both the asset-price bubbles and the structure of the economy is deliberately kept extremely simple and stylised. For example, the model allows for no forward-looking element in the formation of inflation expectations, so limiting the scope for monetary policy to influence the economy through pre-commitment to a particular monetary policy path or approach. Furthermore, the asset-price bubbles in the model are treated in a simple, reduced-form fashion, in terms of their impact on real activity, without any attempt to model the bubble formation process itself.

The reason for these choices is that much of the discussion about how monetary policy should react to asset-price bubbles focusses on the extreme informational difficulties that policy-makers face in determining the properties of a given bubble (current size, likelihood of collapse), or whether a bubble even exists. These informational difficulties are often cited as a principal reason why an activist approach to monetary policy in the face of asset-price misalignments might be difficult or sub-optimal in practice. However, by using a highly simplified model of the economy, in which policy-makers are also endowed with full knowledge of the stochastic properties of a developing asset-price bubble, Gruen et al (2003) were able to abstract from these informational issues. By doing so, they were able to demonstrate that there are other factors, besides informational constraints, which complicate an approach of actively responding to asset-price bubbles - to the point of sometimes making it problematic even to know whether policy ought to be set more tightly or more loosely than it would otherwise be, absent the bubble.

Our adoption in this paper of the same simplified modelling framework as Gruen et al (2003) should be viewed in the same spirit. In particular, the reason 
that we do not attempt to provide a more explicit or detailed model of asset prices in this paper is simply that doing so is not a focus of the paper. Rather, extending the work of Gruen et al, we wish to study whether or not it is clear-cut in what way the presence of a ZLB on nominal interest rates would influence policy-makers, attempting to handle a developing asset-price bubble, even when in possession of a good understanding of the stochastic properties of the bubble's likely future impact on the real economy. The same rationale applies to our choice of a simple and transparent modelling framework which excludes any forward-looking element to the inflation expectations formation process. Excluding such an element does not indicate that the management of future expectations might not be an important tool in the armoury of a central bank, especially as the economy approached the ZLB. Rather, it simply reflects that our aim in this paper is to highlight other factors which would - even were such management of future expectations possible - still complicate the task of policy-makers trying to determine how, optimally, to respond actively to a developing bubble. ${ }^{4}$

Returning to the model itself, last but not least we introduce a zero lower bound on the nominal interest rate into the model described by Equations (3), (4) and (5). It is at this point that our treatment diverges from that in Gruen et al (2003).

In Gruen et al the simplifying assumption is made that policy-makers control the real interest rate, rather than the nominal one, and that this real interest rate can be adjusted arbitrarily, in response to shocks to the economy. Here we drop this latter assumption and require, instead, that the real interest rate never be such that the corresponding level of the nominal rate would be negative.

This requirement may be expressed mathematically by introducing variables $r_{t}^{l v l}$, $i_{t}^{l v l}$ and $\pi_{t}^{l v l}$ for the respective levels of the real interest rate, nominal interest rate and rate of inflation. ${ }^{5}$ Then, writing $r^{*}, i^{*}$ and $\pi^{*}$ for the corresponding neutral or

4 Note that the preceding paragraphs represent a response to some of the issues, regarding the modelling framework adopted in the paper, raised by participants at the 15th Annual East Asian Seminar on Economics, held in Tokyo in June 2003, at which this paper was presented.

5 Variables with a 'lvl' superscript thus represent levels variables, while those without a 'lvl' superscript continue to denote the deviations of these levels variables from their neutral or target values. 
target levels of these variables, the zero lower bound restriction simply becomes the requirement that

$$
i_{t}^{l v l} \geq 0
$$

while the following four identities, primarily relating real and nominal variables, must also be satisfied:

$$
\begin{aligned}
i^{*} & =r^{*}+\pi^{*} \\
\pi_{t}^{l v l} & =\pi^{*}+\pi_{t} \\
r_{t}^{l v l} & =r^{*}+r_{t} \\
i_{t}^{l v l}=r_{t}^{l v l} & +\pi_{t}^{l v l}=i^{*}+r_{t}+\pi_{t} .
\end{aligned}
$$

\subsection{Activist and sceptical policy-makers}

Equations (3) to (10) summarise our Ball-Svensson economy, experiencing an asset-price bubble, and subject to a zero lower bound on nominal interest rates. Returning to the framework employed by Gruen et al (2003), we next introduce two different types of policy-maker: sceptics, who don't try to second-guess asset-price developments, and activists, who believe that they understand enough about asset-price bubbles to set policy actively in response to them.

To draw the distinction more precisely, both types of policy-maker understand how the output gap and inflation evolve over time, as summarised by Equations (4) and (5). Activists also understand, and respond optimally to, the stochastic behaviour of the bubble, as summarised by Equation (3). Sceptics, by contrast, respond to asset-bubble shocks, $\Delta a_{t}$, when they arrive, but assume that the expected value of future shocks is zero.

Such sceptics should not, however, be thought of as naive or ignorant for adopting this position. As an asset-price bubble grows, there is always disagreement about whether the observed asset-price developments constitute a bubble, in which case expectations about future asset-price changes may be non-zero, or are instead consistent with an efficient market, in which case the expected value of future 
changes in the asset price is zero. ${ }^{6}$ In holding that the expected value of future asset-price shocks is zero, sceptical policy-makers in our framework should therefore simply be viewed as believers in the efficient markets hypothesis.

Continuing, we assume that policy-makers observe in each year whether the bubble has grown further, or collapsed, before setting the interest rate for that year. Given the nature of the lags in the model, this year's interest rate will have no impact on real activity until next year, and on inflation until the year after that.

We also assume that our two types of policy-maker have the same preferences, and care about the volatility of both inflation and output. Explicitly, we thus assume that in each year $t$, policy-makers (whether activist or sceptic) recommend the real interest rate, $r_{t}$, which will minimise the weighted sum of the expected future squared deviations of inflation and output from their target levels:

$$
L=\sum_{\tau=t+1}^{\infty}\left[E_{t}\left(y_{\tau}^{2}\right)+\mu E_{t}\left(\pi_{\tau}^{2}\right)\right]
$$

where $\mu$ is the relative weight on the deviations of inflation and $E_{t}$ is the policy-maker's year $t$ expectation. For the baseline results in this paper we set

6 In the late 1990s, precisely this debate was occurring within the US Federal Reserve in relation to the US stock market, as the following quotation from Stephen Cecchetti makes clear.

From August 1997 to June 1999 I sat on the backbench at the meetings of the FOMC and received all of the material distributed to the participants. ... The interesting thing is that during the period when I took part in this process, the Board staff preparing the forecasts invariably assumed that the US stock market would decline significantly - 10 to 20 per cent declines in the Wilshire 5000 index were commonly the basis for the forecasts. They clearly believed that the stock market was overvalued. ...

At the time this was all happening, I confess that I was scandalised. I regularly ranted about the practice of forecasting a dramatic decline in the stock market. Like the vast majority of academics, I adhered to the efficient markets view. ... while we needed to assume something about the stock market, shouldn't we assume the equity index would stay constant at its current level indefinitely? ...

This happened five years ago (which is why I can talk about it now), and in the interim I have changed many of my views. (Cecchetti 2003)

Sceptical policymakers in our framework may be characterised as those who adhere to the approach of Cecchetti - before his change of view! 
$\mu=1$, so that policy-makers are assumed to care equally about deviations of inflation from target and of output from potential.

Finally, in the absence of a zero lower bound on nominal interest rates, it is possible to write down explicitly the form that optimal policy will take for a sceptic in our Ball-Svensson economy. ${ }^{7}$ Ball (1999a) showed that this is given by a Taylor rule, namely

$$
r_{t}=\beta^{-1}(\lambda+\alpha q) y_{t}+\beta^{-1} q \pi_{t}
$$

where the scalar $q$ is defined by $q=\left(-\mu \alpha+\left(\mu^{2} \alpha^{2}+4 \mu\right)^{1 / 2}\right) / 2$. For our baseline parameter values, this becomes

$$
r_{t}=1.13 y_{t}+0.82 \pi_{t}
$$

which is a more aggressive Taylor rule than the 'standard' one introduced by Taylor (1993), $r_{t}=0.5 y_{t}+0.5 \pi_{t}$.

In the presence of a zero lower bound on nominal interest rates, however, it may not be possible for a sceptic (or an activist, after the bubble has burst) to recommend policy in accordance with Equation (12). Instead, optimal policy for such a policy-maker must now take the form

$$
r_{t}=\max \left(\beta^{-1}(\lambda+\alpha q) y_{t}+\beta^{-1} q \pi_{t}, r_{t}^{z l b}\right)
$$

where $r_{t}^{z l b}$ denotes the value of $r_{t}$ which corresponds to $i_{t}^{l v l}=0$, namely

$$
r_{t}^{z l b}=-i^{*}-\pi_{t}
$$

\section{How Might the Zero Lower Bound Influence an Activist Policymaker?}

In Section 4 we describe our empirical results as to how the presence of a zero lower bound on nominal interest rates influences the policy recommendations of an activist policy-maker, confronting a developing asset-price bubble. We

7 This reflects that, in the absence of the zero lower bound, certainty equivalence holds in the model, for a policy-maker who expects no future asset-price driven shocks to output. Such policy-makers in fact include not only sceptics in each period, but also activists once the bubble bursts (since it is assumed never to re-form). 
also explore the implications of these results for policy questions such as the appropriate choice of inflation target, and how this may depend on key economic parameters which may vary from country to country.

Before turning to these empirical results, however, it is instructive to ask: what effect, intuitively, would we expect the existence of the ZLB to have on an activist policy-maker, weighing how best to respond to an asset-price bubble? In the remainder of this section, we address this question in two stages: first for asset-price bubbles whose development (period-to-period growth and/or probability of bursting) is completely exogenous; and secondly for asset-price bubbles whose development can be influenced by policy.

Note that our focus here, and throughout what follows, is on the marginal effect which the ZLB might have on an activist policy-maker, over and above whatever impact the bubble itself would have even in the absence of a ZLB on nominal interest rates. Thus, when we refer to the ZLB causing an activist to (say) loosen policy in a given period, we are not necessarily implying that they would recommend policy which is actually looser than a sceptic in that period. Rather, we mean simply that they would recommend policy, in that period, which is not as tight as they would otherwise recommend, were there no ZLB.

\subsection{The case of bubbles whose development is exogenous}

Consider an asset-price bubble whose period-to-period growth and probability of bursting are entirely exogenous, unaffected by monetary policy. Suppose also that an activist policy-maker understands that he is powerless to influence the future trajectory of this bubble.

As such a bubble grows, the activist appreciates the increasing risk that, in the future, its eventual bursting will generate a large negative shock to output and, thereafter, to inflation, which might result in the activist's preferred post-bubble policy recommendations striking the ZLB. This latter effect could occur either: immediately, if the output gap is driven sufficiently negative to result in the optimal nominal interest rate falling below zero in the period of the bubble's collapse; or in subsequent periods, as the shock to output flows into lower inflation (or even deflation), so that a lower nominal interest rate is required to reach a desired real interest rate setting. 
Such a situation, in which the policy-maker's capacity to stabilise the economy would be constrained, would clearly be sub-optimal. Indeed, in the extreme, it might even result in the economy entering a deflationary spiral from which, owing to the ZLB, monetary policy alone would be unable to rescue it. Intuitively, therefore, an activist policy-maker would prefer to prevent such an outcome arising in the future - even at some definite present cost in terms of their loss function, Equation (11).

In our Ball-Svensson model, however, the only available defence against such an outcome, for an exogenous bubble, is to recommend policy so as to raise both the output gap and inflation a little, relative to what would otherwise be optimal in the absence of the ZLB. Such a cushion of extra output and inflation would reduce the likelihood of policy subsequently striking the ZLB, either in the immediate aftermath of the bubble's collapse, or in subsequent periods. Hence, one would expect an activist policy-maker, concerned about the ZLB, to be marginally less hawkish than otherwise, when deciding how best to deal with a developing exogenous asset-price bubble.

This intuition may be neatly illustrated using a phase diagram for the Ball-Svensson model introduced by Reifschneider and Williams (2000). This phase diagram depicts how $\left(y_{t}, \pi_{t}\right)$-space may be sub-divided into three distinct regions, in each of which monetary policy has a differing capacity to return the economy to steady state (output at potential and inflation at target), in the absence of future shocks. This phase diagram is shown in Figure 1 below, for the case where $\alpha, \beta, \lambda$ and $\mu$ take their baseline values. A detailed derivation of this phase diagram, which differs from that provided by Reifschneider and Williams (2000), is set out in Appendix B.

In Region I, monetary policy is able to return the economy to steady state (absent future shocks), without ever striking the zero lower bound on nominal interest rates. By contrast, in Region II, monetary policy is still able to return the economy to steady state (absent future shocks), but is initially constrained in doing so by the ZLB - so that the economy's path back to $\left(y_{t}, \pi_{t}\right)=(0,0)$ would be sub-optimal (higher loss), relative to that which could be achieved if nominal interest rates were not bounded below. Finally, in Region III, monetary policy alone is unable to prevent the economy entering a catastrophic deflationary spiral. Such a fate could only be able to be averted by the advent, as a supplement to expansionary 


\section{Figure 1: Phase Diagram for the Ball-Svensson Model under Optimal Policy}

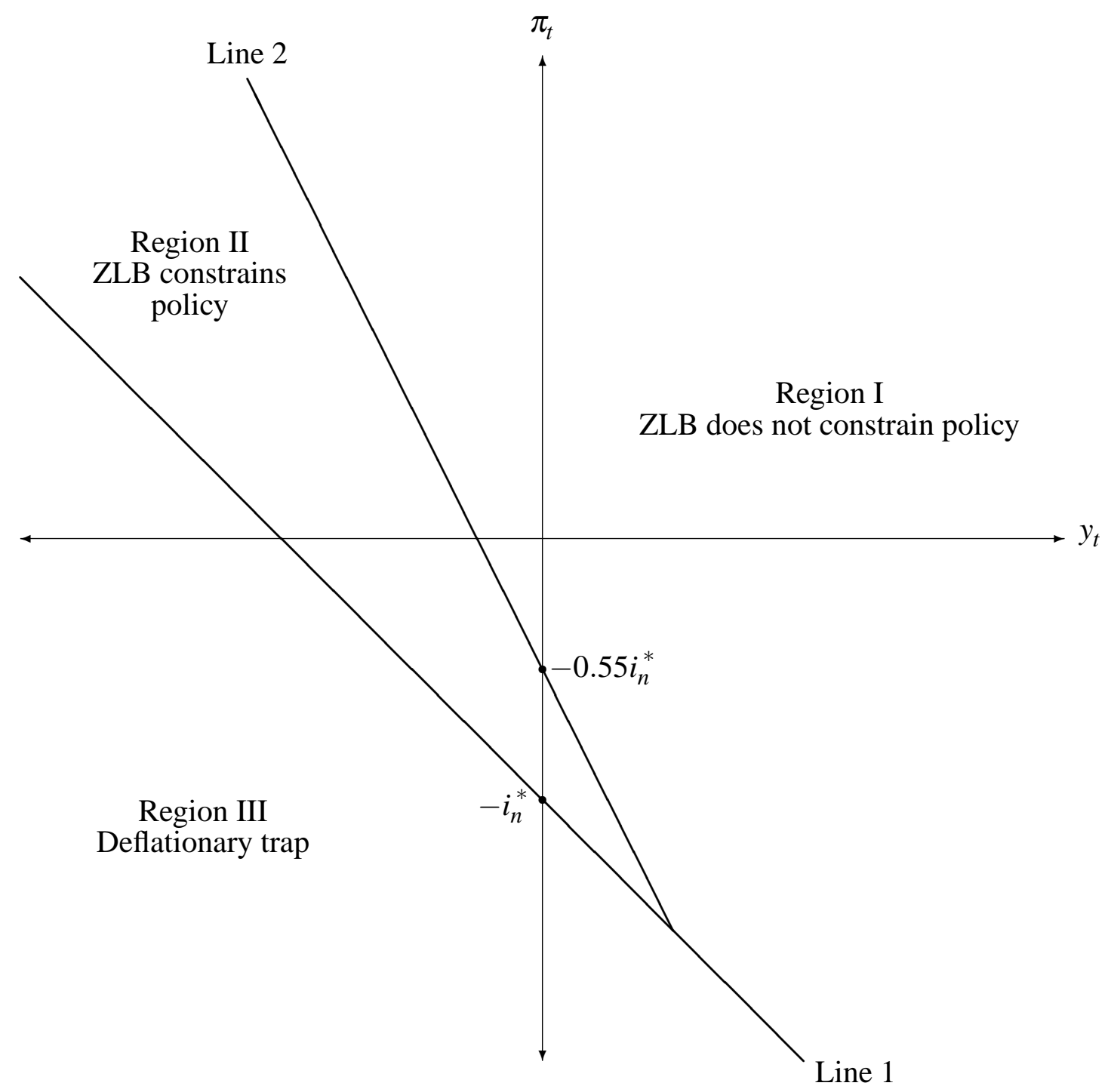

Notes: Phase diagram for the case where the parameters $\alpha, \beta, \gamma$ and $\mu$ take their baseline values. Line 1 passes through the point $\left(0,-i_{n}^{*}\right)$ and has approximate slope -0.54 . Line 2 passes through the point $\left(0,-0.55 i_{n}^{*}\right)$ and has approximate slope -0.62 .

monetary settings, of sufficiently powerful future positive shocks to the economy: either exogenous, such as a boom in world growth; or generated through other arms of policy, such as a fiscal expansion.

Now consider again an activist policy-maker in our Ball-Svensson economy, confronted with a developing exogenous asset-price bubble, and with no policy tools at his disposal other than the interest rate. Clearly, he will wish to take whatever steps are necessary to prevent the economy ever entering Region III - 
since this would inescapably result in devastating future losses. He will also prefer to keep the economy from entering Region II, since in this region the ZLB would prevent output and inflation from being returned to steady state as efficiently as possible, so incurring additional costs in terms of his loss function, Equation (11).

If we combine these observations with the fact that, whenever the bubble does burst, the nature of the resultant shock to the economy will be to shift it horizontally to the left in $\left(y_{t}, \pi_{t}\right)$-space, by an amount equal to the size of the bubble, then the incentives for our activist policy-maker become clear. To ensure that the economy never enters Region III, and to also keep it out of Region II if possible, he will prefer to recommend policy, while the bubble survives, which pushes the economy up and to the right in $\left(y_{t}, \pi_{t}\right)$-space, relative to what he would recommend were there no ZLB. Moreover, he will prefer this even if it may take the economy further away from steady state at $\left(y_{t}, \pi_{t}\right)=(0,0)$, and so incur an immediate cost in terms of his loss function, Equation (11).

Finally, Figure 1 also highlights two further points about the extent to which the ZLB will influence an activist policy-maker's interest rate recommendations. The first is that, the bigger the current size of the bubble, the further such a policy-maker will wish to push the economy upwards and to the right in $\left(y_{t}, \pi_{t}\right)$-space, to minimise its chances of being driven into Regions II or III whenever the bubble does collapse. Hence, the bigger the current size of the bubble, the greater will be the influence which the ZLB will have on an activist's policy recommendations.

The second point rests on the observation that the locations of the boundary lines separating Regions II and III from the rest of $\left(y_{t}, \pi_{t}\right)$-space are both determined by the level of the neutral nominal interest rate, $i^{*}$. The higher is $i^{*}$, the further these boundary lines will be pushed down and to the left, away from the origin in $\left(y_{t}, \pi_{t}\right)$-space. Hence, the higher is $i^{*}$, the less of a concern will the risk of entering Regions II or III be to an activist policy-maker - and so the less will such a policy-maker feel the need to recommend interest rate settings, while the bubble survives, which hold both the output gap and inflation higher than they would otherwise prefer.

This latter point is, of course, simply another way of saying that the higher are both the neutral real rate of interest in the economy and the target rate of inflation, the less of a factor will the ZLB be in the minds of policy-makers, when dealing 
with an asset-price bubble. Hence, while there are clearly costs associated with operating the economy at too high an average inflation rate, policy-makers may also wish to take care not to adopt too low a figure when deciding upon an inflation target - especially if the neutral real interest rate in their economy is relatively low.

\subsection{The case of bubbles whose development is affected by policy}

For an entirely exogenous asset-price bubble, we have just seen that the presence of a zero lower bound on nominal interest rates provides an incentive to an activist policy-maker to recommend somewhat looser policy than otherwise, so as to shift the economy upwards and to the right in $\left(y_{t}, \pi_{t}\right)$-space. The optimal extent of such insurance against striking the ZLB will be greater the larger is the current size of the bubble, and the lower is the economy's neutral nominal interest rate in steady state.

For a bubble whose development (period-to-period growth and/or probability of bursting) is affected by policy, however, the situation is no longer so clear. Consider first the case of a bubble whose probability of bursting next period is increased (decreased) by setting policy more tightly (loosely) in the current period.

In this event, although the marginal effect of loosening policy would be to shift the economy away from Regions II and III in $\left(y_{t}, \pi_{t}\right)$-space, it would also be to increase the odds of the bubble surviving and growing next period, so posing a greater risk down the track. Hence, the direction in which the ZLB would influence the recommendations of an activist policy-maker is no longer clear-cut. Indeed, for a bubble which was very sensitive to policy, one could imagine the ZLB providing an incentive for an activist policy-maker to raise interest rates decisively early in the bubble's life - in the hope of bursting it before it could grow sufficiently to pose a serious threat to the stability of the economy upon its collapse.

A similar story holds for the case of a bubble whose period-to-period growth, while it survives, may be influenced by policy. Suppose that an activist policy-maker knows that the bubble's growth next period, if it survives, will be reduced (increased) by setting policy more tightly (loosely) in the current period.

In this event, loosening policy in any given period would again have the effect of shifting the economy away from Regions II and III in $\left(y_{t}, \pi_{t}\right)$-space - by a greater amount, indeed, should the bubble survive, than the same loosening would achieve 
in the case of a purely exogenous bubble. However, it would also have the effect of further boosting the size of the bubble, in the event that it did not burst next period, hence increasing the size of the negative shock to the economy whenever the bubble ultimately does burst. Hence, once again, the direction in which the presence of a ZLB on nominal interest rates would, at the margin, push an activist policy-maker in this situation is no longer clear.

\subsection{An insurance interpretation for the implications of the ZLB}

The observations in Sections 3.1 and 3.2 may be neatly summarised in terms of the phase diagram, Figure 1, and an 'insurance' paradigm for thinking about how the presence of a ZLB on nominal interest rates might influence the thinking of an activist policy-maker. As illustrated in Figure 1, the presence of a ZLB creates two zones in $\left(y_{t}, \pi_{t}\right)$-space, Regions II and III, which an activist policy-maker will be either desperate (Region III) or at least anxious (Region II) to keep the economy away from. As an asset-price bubble grows, such a policy-maker will therefore wish to take out some insurance against the economy being driven into either of these regions, whenever the bubble finally does collapse.

For the case of an exogenous bubble, the only such insurance which an activist can set out to purchase - that is, obtain at some definite cost in terms of their objective function, Equation (11) - is to manoeuvre the economy upwards and to the right in $\left(y_{t}, \pi_{t}\right)$-space, by recommending policy be set more loosely than otherwise.

For a bubble whose development (period-to-period growth and/or probability of bursting) is affected by policy, however, alternative potential forms of insurance are available, besides this standard type. If the bubble's probability of bursting is influenced by policy, this alternative insurance takes the form of increasing the odds that the bubble will collapse while it is still young, before it has grown big enough to drive the economy into Regions II or III through its collapse. If instead the bubble's growth may be curtailed by running policy more tightly, it takes the form of restraining the potential future size of the bubble, so as to again ensure that the negative shock which the bubble imparts upon bursting will not be large enough to drive the economy into Regions II or III.

In both these latter cases, these alternative forms of insurance entail setting policy more tightly than otherwise, rather than more loosely, as was the case for the standard form of insurance. For endogenous bubbles, therefore, it is no longer clear 
a priori which form of insurance an activist policy-maker will prefer to purchase, and therefore in which direction the ZLB will alter his policy recommendations. This will depend upon the relative costliness of the different forms of insurance available - which will, in turn, vary from period to period, reflecting the state in which the activist finds the economy (i.e. current output gap and inflation rate, as well as current size of the bubble) when deciding his preferred policy settings.

\section{Results}

In this section we present the optimal policy recommendations of activist and sceptical policy-makers, through time, in the presence of an asset-price bubble. As noted in Section 2, we focus on the period while the bubble survives and grows. Once the bubble bursts, both activists and sceptics in our Ball-Svensson model will always agree on an approach of aggressively easing policy, to counteract the contractionary effects of the bust.

As in Gruen et al (2003), we wish to examine the optimal policy recommendations of sceptics and activists over a range of plausible alternative assumptions about the stochastic nature of the bubble. To do so meaningfully, it is necessary that the two policy-makers face an economy in the same state in each year. Since the current state of the economy depends on previous policy settings (as well as on the evolution of the bubble) we will assume throughout that the policy settings that are actually implemented each year are those chosen by the sceptic. We can then sensibly compare, as each year passes, the current optimal policy recommendations made by the different policy-makers.

The activist's recommendations will depend on the assumptions he makes about the future possible paths of the bubble. In particular, they will reflect the shocks implicit in these paths, and how these shocks interact with both: his preferences, as reflected in his loss function, Equation (11); and the potential constraint on his future actions embodied in the ZLB. By contrast, the recommendations of the sceptic - being a believer in the efficient markets hypothesis - will reflect an expectation of no future shocks to the economy flowing from asset-price movements. 


\subsection{Baseline Results: The Case of Exogenous Bubbles}

We begin with results for the baseline case where: the bubble's future development is unaffected by policy-makers' actions; its direct expansionary effect on output in each year of its growth is a constant 1 per cent $\left(\gamma_{t}=1\right)$; its period-to-period probability of bursting is a constant 40 per cent $\left(p_{t}=p^{*}=0.4\right)$; and the model and loss function parameters $\alpha, \beta, \lambda$ and $\mu$ take their baseline values specified earlier. ${ }^{8,9}$ In subsequent subsections we will examine the effect of varying each of these sets of assumptions. ${ }^{10}$

Figure 2 shows the optimal policy recommendations made, in each period, by the sceptic and two activists, assuming that the steady-state neutral nominal interest rate in the economy is $i^{*}=3$ per cent. ${ }^{11}$ The two activists differ in the way that their actions are influenced by the ZLB. For the first, the ZLB is a genuine constraint on policy, as encapsulated by Equation (6). For the (hypothetical)

8 Recall that these baseline values are $\alpha=0.4, \beta=1.0, \lambda=0.8$ and $\mu=1.0$. Note also that, to ease the process of numerically determining optimal paths of contingent policy recommendations for an activist policy-maker in each period, we actually make the simplifying assumption here and in all subsequent scenarios that, if the bubble survives until year 14 (which is an extremely unlikely event for all the parameter values we consider), then it bursts with certainty in that year. Hence, strictly speaking, our assumption regarding $p_{t}$ here is that $p_{t}=p^{*}=0.4$ for all $t=0,1, \ldots, 13$, while $p_{14}=1$.

9 For reference, if $p_{t}$ were 0.4 for all $t$ this would imply an average remaining life for the bubble of two and a half years. However, since $p_{t}=0.4$ here only for $t=0,1, \ldots, 13$, with $p_{14}=1$, our exogenous bubble in this subsection has an expected remaining life in period 0 of just under two and a half years.

10 A variation which we do not examine in the main body of the paper, but which we take up in Appendix C, is the case of rational bubbles. As discussed in Gruen et al (2003), there is a sense in which the baseline bubble just described could, under plausible assumptions about the relationship between the price growth underlying an asset bubble and the impact of that bubble on the real economy, be regarded as irrational. While we do not see this as a shortcoming per $s e$ - since there is much evidence in developed economies of irrational bubbles occurring in practice (see, for example, Shiller (2000)) - it is nevertheless interesting to examine whether the imposition of a rationality assumption on our bubbles would affect the overall thrust of our findings and, if so, how. The results, set out in Appendix C, suggest that it would not.

11 Since $i^{*}=r^{*}+\pi^{*}$, this might represent an economy where the neutral real rate, $r^{*}$, is 2 per cent, and target inflation, $\pi^{*}$, is 1 per cent; or where $r^{*}=3$ per cent and $\pi^{*}=0$ per cent; or any other such combination. 
second, the zero lower bound is not a constraint, so that a negative nominal interest rate setting can (in some unspecified way) be achieved, if desired.

\section{Figure 2: Real Interest Rate Recommendations While the Bubble Survives}

Policy has no effect on the bubble, $i^{*}=3.0$

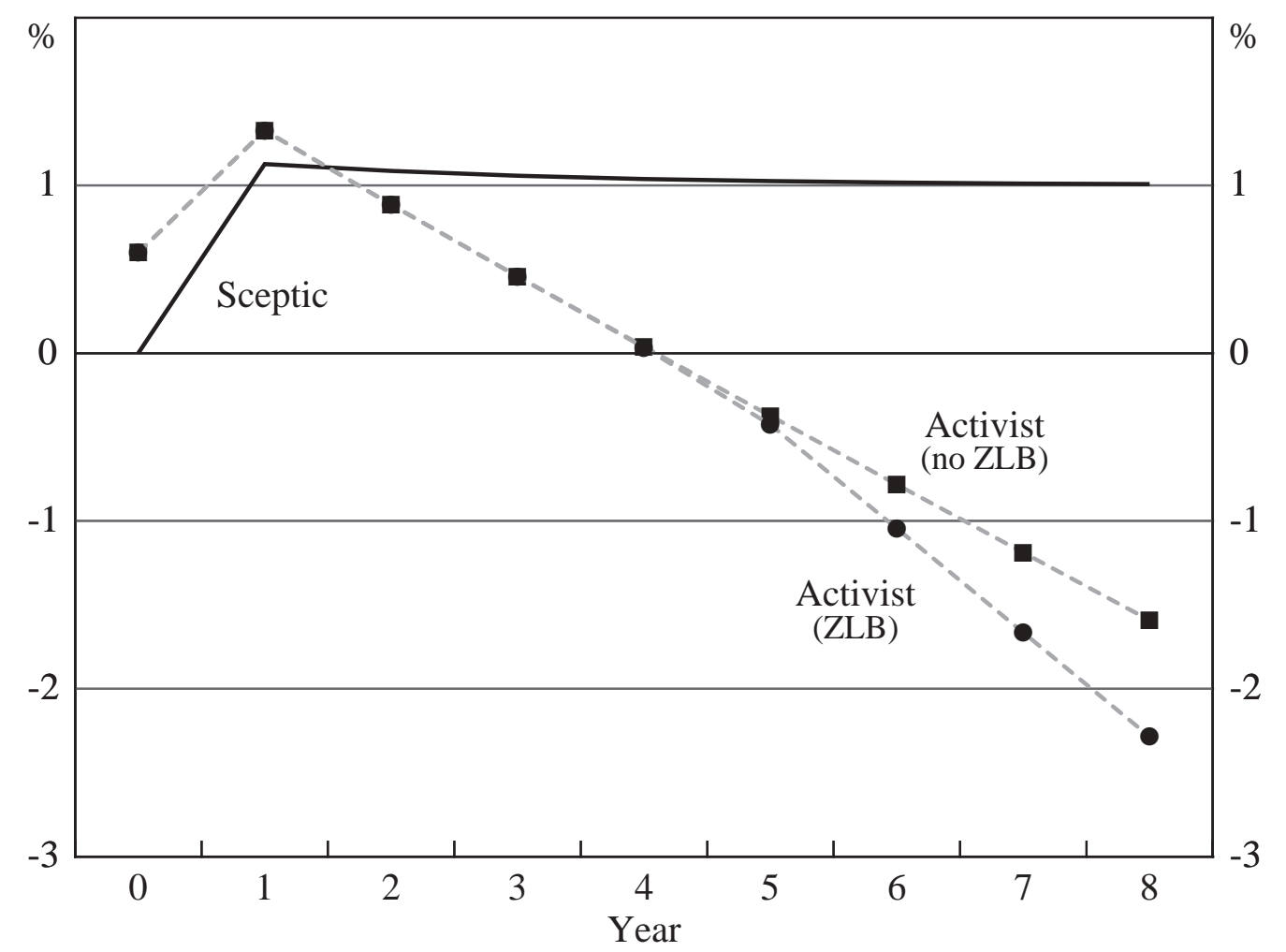

Notes: The sceptic implements policy in each year. Real interest rates are deviations from neutral.

The main features of Figure 2 - the shapes of the paths recommended by the sceptic and the 'no ZLB' activist; and the fact that the recommendations of this activist, while initially above those of the sceptic, subsequently drop below them - were discussed in Gruen et al (2003). We refer the reader to that paper for a detailed analysis of the policy implications of these features, and an intuitive explanation of them (in terms of the interaction between the future possible effects of the bubble on output, and the lag with which policy affects the economy).

Our focus in this paper, however, is on the difference between the two sets of activist policy recommendations shown in Figure 2. This difference captures the impact of the presence of the ZLB on an activist policy-maker's preferred recommendations. Two characteristics of this difference stand out. First, as anticipated in Section 3, for an exogenous bubble the effect of the zero lower 
bound is indeed to make an activist reduce his policy recommendations in each period, at the margin, relative to what he would have recommended were there no ZLB. Secondly, even for an economy with a low steady-state neutral nominal interest rate of $i^{*}=3$ per cent, this effect is, however, very small at first - and remains so, at least until such time as the bubble has become quite large. ${ }^{12}$

We can explore these latter two observations further, by considering how the impact of the ZLB on an activist policy-maker varies with the level of the steady-state neutral nominal interest rate in the economy, $i^{*}$. Figure 3 below shows the difference between the policy recommendations of activist policy-makers, with and without a zero lower bound constraint, for $i^{*}=1,2,3,5.5$ and 8 per cent. ${ }^{13}$

We see that for neutral nominal interest rates around or above the range currently estimated for Australia, the ZLB is not a factor in an activist policy-maker's thinking, even for quite large bubbles. By contrast, in an economy with an extremely low steady-state neutral nominal interest rate, such as $i^{*}=1$ or 2 , the ZLB would start to become a serious factor in an activist policy-maker's considerations even for small to moderate sized bubbles. ${ }^{14}$

We now examine how these observations vary across a range of alternative assumptions about either the stochastic properties of our asset-price bubbles, or about the model parameters $\alpha, \beta$ and $\lambda$.

\subsection{Exogenous Bubbles with Different Probabilities of Bursting}

The results in Figure 2 suggest that, for an exogenous bubble with period-to-period probability of bursting $p_{t}=p^{*}=0.4$, the ZLB is not a major factor in an activist policy-maker's considerations, unless the steady-state neutral nominal interest rate

12 It is not until period 6 that an activist, in such an economy, would feel the need to lower his policy recommendation by 25 basis points on account of concern about the ZLB.

13 The choice of $i^{*}=5.5$ per cent is covered to include a case in the plausible range of values for Australia: corresponding to, say, a neutral real interest rate of 3 per cent and an inflation target of 2.5 per cent, the mid-point of the 2 to 3 per cent medium-term target band. This value also lies neatly in the middle of the 5 to 6 per cent range in which most current estimates of the neutral nominal interest rate for Australia fall. The choices $i^{*}=1$ and 2 per cent are included to show the increasingly severe impact of the ZLB on an activist policy-maker's considerations, when the neutral nominal rate is extremely low. 


\section{Figure 3: Impact of the ZLB on an Activist's Recommendations}

\section{Difference between recommendations with and without the ZLB}

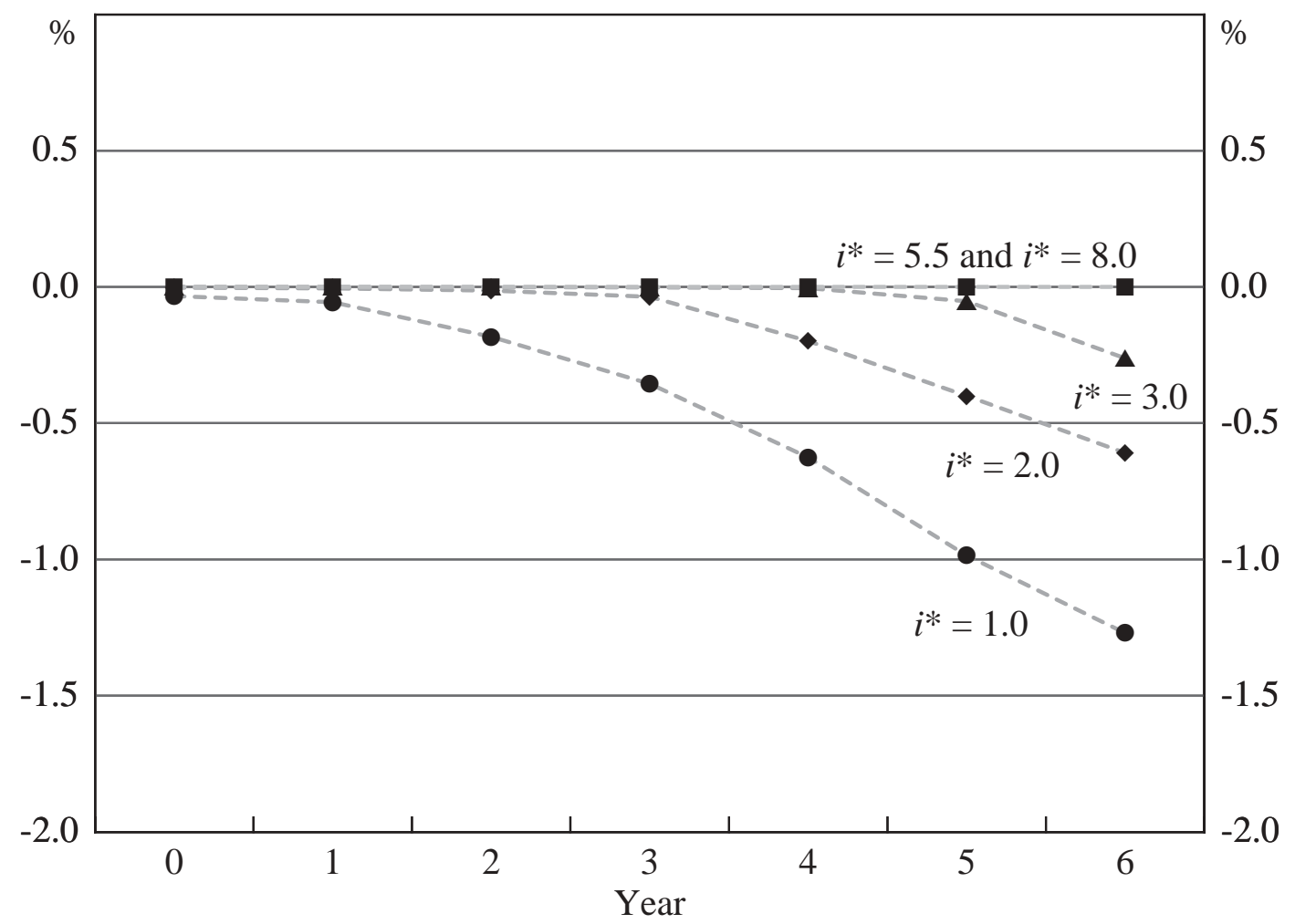

Notes: The sceptic implements policy in each year.

14 There is a technical caveat which should be borne in mind in relation to the results reported in Figures 2 and 3. This relates to the fact that the presence of the ZLB on nominal interest rates results in an activist policy-maker's expected loss ceasing to be a quadratic function of his contingent policy recommendations. This means that, in each period, not only must we resort to numerical methods to seek an activist's loss minimising profile of contingent policy recommendations, but we must also be concerned about the possibility of inadvertently locating a local rather than global minimum. To help overcome this potential problem we adopted the following safeguards throughout the simulations reported in this paper. First, we set up the loss minimisation process using two different algorithms, to provide a cross-check on our results. Secondly, having located notionally optimal sets of contingent policy recommendations for each period, in a given scenario, we then subjected these profiles to random perturbations, to see whether re-optimisation starting from these perturbed settings would return the original profile, or instead give rise to an alternative with lower expected loss. Finally, these perturbation tests were separately carried out in various instances by each author, to try to maximise variety in the alterations tested. To the extent that these safeguards may have failed in any particular instance, this would simply highlight the practical difficulties facing an activist policy-maker in trying to determine how to respond optimally to a developing asset-price bubble in such circumstances, even with perfect knowledge about both the structure of the economy and the stochastic properties of the bubble! 
in the economy is extremely low. It is interesting to ask whether this remains so as we vary the constant probability of bursting, $p^{*}$.

For small values of $p^{*}$, the probability that the bubble will continue to grow to a large size, rather than burst in the near term, increases. We would therefore expect that, the smaller the value of $p^{*}$, the greater would be the importance of the ZLB in an activist policy-maker's thinking, as a possible constraint on future action.

Figure 4: Impact of the ZLB on an Activist's Recommendations

Sensitivity to alternative values for $\mathrm{p}^{*}, \mathrm{i}^{*}=3.0$

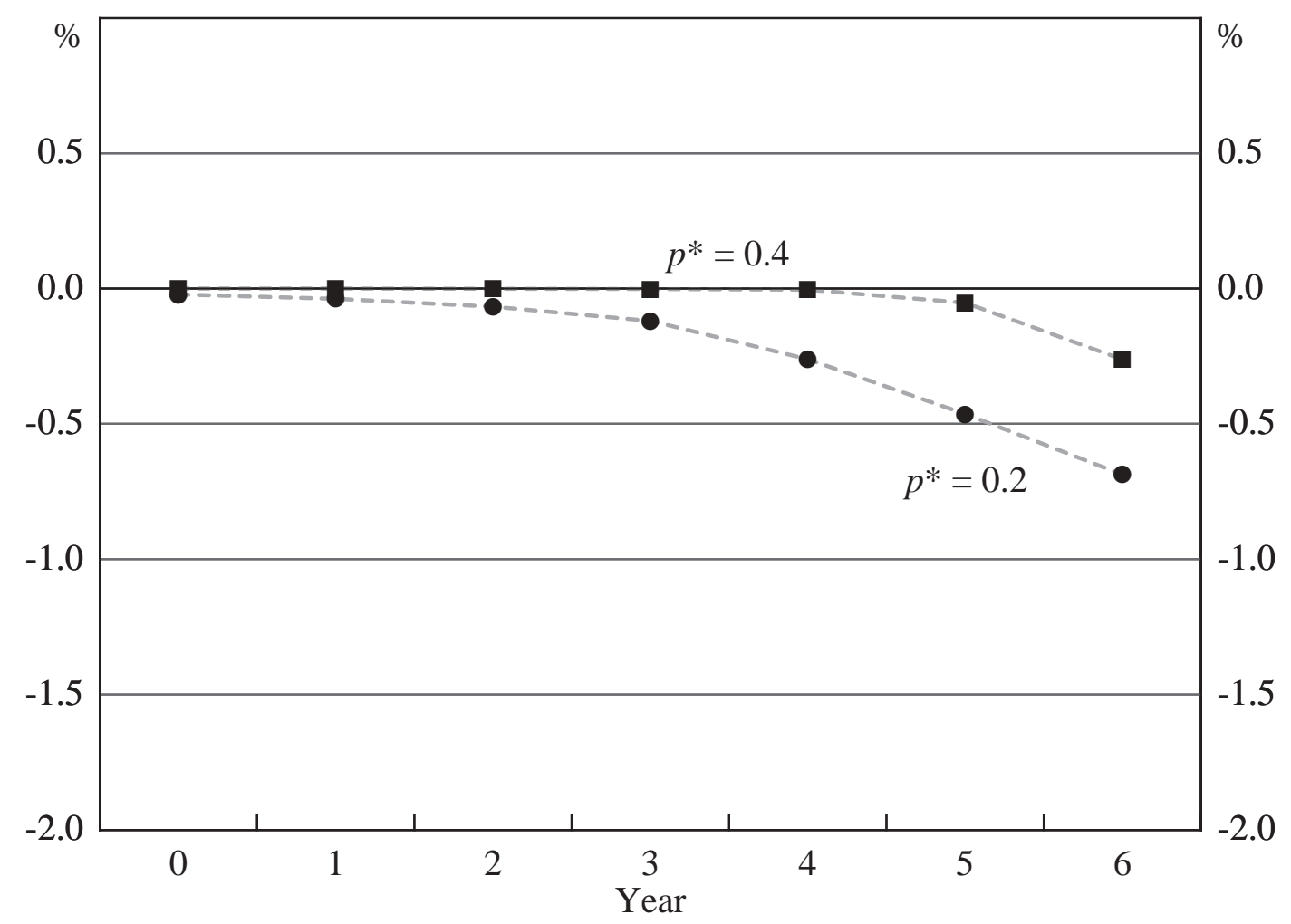

Notes: The sceptic implements policy in each year.

As Figure 4 shows, this is indeed what we find. For an exogenous bubble whose period-to-period probability of bursting is $p_{t}=p^{*}=0.2$, the impact of the ZLB on an activist's recommendations is apparent both earlier and more forcefully than in the case where $p_{t}=p^{*}=0.4 .^{15,16}$ Nevertheless, the scale of this 'ZLB effect'

15 Note that an activist's policy recommendations themselves are, however, tighter in every period for a bubble with $p_{t}=p^{*}=0.2$ than for a bubble with $p_{t}=p^{*}=0.4$. This is true with or without the ZLB constraint on nominal interest rates - for the case without the ZLB constraint see Gruen et al (2003), Figure 2. 
is not very large in either case, nor is it dramatically different between the two cases, at least until the bubble has become quite large.

\subsection{Bubbles whose Growth is Affected by Policy}

In Sections 4.1 and 4.2 we considered only purely exogenous asset-price bubbles. A natural extension is to assume that, by setting tighter policy this year, policy-makers can reduce the extent of the bubble's growth next year, if it survives. Explicitly, we assume once again that $p_{t}=p^{*}=0.4$ (except $p_{14}=1$ ), but that now, following Gruen et al (2003),

$$
\gamma_{t}=1-\phi\left(r_{t-1}-r_{t-1}^{*}\right)
$$

where: $r_{t}^{*}, t \geq 0$, denotes the optimal path chosen by a sceptical policy-maker while the bubble survives, assuming $\gamma_{t}=1$; and $\phi$ is a sensitivity parameter to be chosen. ${ }^{17}$ For the results which follow we assume $\phi=1$, so that by setting policy 1 percentage point higher than the sceptic this year, the bubble's growth next year would be reduced from 1 per cent to nothing. ${ }^{18}$

In this setting, and for an economy with $i^{*}=3$, Figure 5 shows a comparison of the optimal interest rate recommendations of a sceptic and 3 activists, while the bubble survives. Two of these activists differ in their assumptions about the sensitivity

16 The 'ZLB effect' is around 25 basis points by year 4, and 50 basis points by year 5 , when $p^{*}=0.2$, whereas it is not until year 6 that it even reaches 25 basis points when $p^{*}=0.4$.

17 We choose the functional form in Equation (16) so that, for the benchmark policy settings chosen by the sceptic, $\gamma_{t}=1$ for all $t$, as in the exogenous bubble case. Note also that in Equation (16) the growth of the bubble this period depends upon last period's interest rate. An interesting variant, suggested to us by Kenneth Kuttner, would be to allow for monetary policy to have a contemporaneous impact on asset prices (while continuing to affect the output gap directly with a one-period lag). If suitably incorporated, such a change might allow policy-makers to provide a brake on the fall of asset prices, whenever a bubble burst, so cushioning the impact of the burst on aggregate demand. Of course, knowledge that the monetary authorities might behave in this way might, however, risk creating a moral hazard problem, along the lines of the so-called 'Greenspan put' discussed in relation to the recent tech stock boom and bust in the US. For reasons of space, we do not pursue these various issues further here.

18 To continue holding the bubble's growth to zero, while it survives, would of course require policy to be set 1 percentage point higher than the sceptic in each such period - with the usual consequences of tight policy for both output and inflation. 
parameter $\phi$, with one assuming no interest-rate sensitivity, $\phi=0$, while the other assumes high sensitivity, $\phi=1$. The third, for reference, is a hypothetical policy-maker who also assumes high sensitivity $(\phi=1)$, but is unconstrained by the ZLB.

\section{Figure 5: Real Interest Rate Recommendations While the Bubble Survives}

Policy affects the bubble's growth, $i^{*}=3.0$

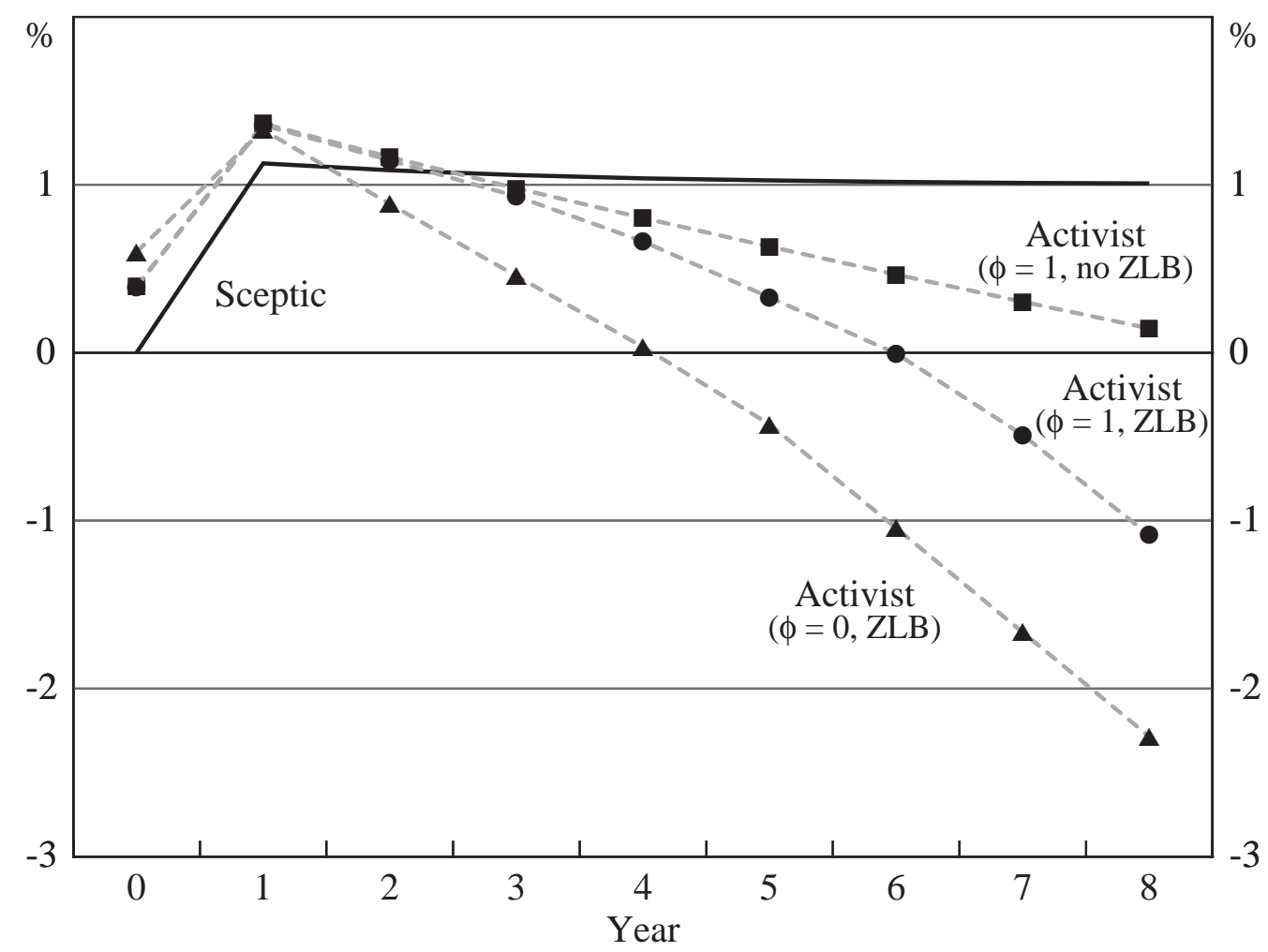

Notes: The sceptic implements policy in each year. Real interest rates are deviations from neutral.

As discussed in Gruen et al (2003), we see first that being able to influence the growth of the bubble makes an activist policy-maker increase their policy recommendations in each period from year 1 onwards, relative to what they would advise were they unable to influence the bubble's growth. However, the impact of the ZLB is still to reduce such an activist's policy recommendations, relative to what they would prefer in the absence of the ZLB. Moreover, this 'ZLB effect' now manifests itself both earlier and more strongly than in the previous setting of an exogenous bubble. ${ }^{19}$

We can interpret these latter results in terms of the 'insurance framework' for analysing the impact of the ZLB, described in Section 3. Recall that, for bubbles 
whose growth is affected by policy, two alternative forms of insurance against encountering the ZLB are available to an activist policy-maker: building a buffer of inflation and output against the effects of the bubble's eventual collapse, by running policy more loosely than otherwise; or holding down the size of the bubble, and hence the size of the negative shock it will impart upon bursting, by running policy more tightly than otherwise.

The fact that the 'ZLB effect' in Figure 5 is again downwards shows first of all that, for a Ball-Svensson economy with our baseline parameters and a neutral nominal interest rate of $i^{*}=3$, the former type of insurance must be more cost-effective than the latter, against a bubble whose growth can be influenced by policy according to Equation (16) with $\phi=1$. As for the observation that this 'ZLB effect' is now evident both earlier and more strongly than for an exogenous bubble, this reflects the presence of two added feedbacks in this setting, relative to the exogenous bubble case - between an activist's recommendations, on the one hand, and the structure of Equation (16), on the other.

In more detail, suppose that, in the current setting, an activist is contemplating recommending looser policy than otherwise, on account of the future risks arising from the ZLB (as Figure 5 shows he will do). For each basis point by which he does so, he is aware that this will now have the effect of increasing the expected growth of the bubble next period, if it survives, by an equal amount. This will have two competing effects. On the one hand it will partially offset the decrease in these future risks which he would hope to achieve through the loosening of policy, and so require him to recommend policy be moved further, to achieve his optimal level of insurance, than he would in the exogenous bubble case. On the other, it will provide him with a greater cushion of output and (future) inflation than otherwise, and so reduce the extent of loosening he may feel is required. The results in Figure 5, which show the magnitude of the 'ZLB effect' accelerating

19 The claim of a stronger effect is based on comparing the difference between the 'Activist $(\phi=1$, ZLB)' and 'Activist ( $\phi=1$, no ZLB)' lines in Figure 5, on the one hand, with that between the 'Activist (ZLB)' and 'Activist (no ZLB)' lines in Figure 2, on the other. Note also that the caveat expressed in footnote 14 about our earlier results, namely the possibility of our having inadvertently located local rather than global minima of our activists' loss functions, continues to apply. Indeed, if anything, it is likely to apply with even greater force in both this subsection and (especially) the next, since the ability of policy-makers to influence the bubble's behaviour in these two scenarios would already cause an activist's expected loss to cease to be a quadratic function of his contingent policy recommendations, even in the absence of the ZLB. 
over time relative to its size in the exogenous bubble case, suggest that it is the former feedback which dominates, in the current setting.

Once again, it is interesting to consider the sensitivity of these results to changes in the assumed steady-state neutral nominal interest rate of the economy. This is illustrated in Figure 6, which shows the difference between the policy recommendations of activist policy-makers, with and without a zero lower bound constraint, for $i^{*}=1,3$ and 8 per cent. Here, these activists assume again that policy can affect the bubble's growth according to Equation (16) with $\phi=1$.

Figure 6: Impact of the ZLB on an Activist's Recommendations

Policy affects the bubble's growth

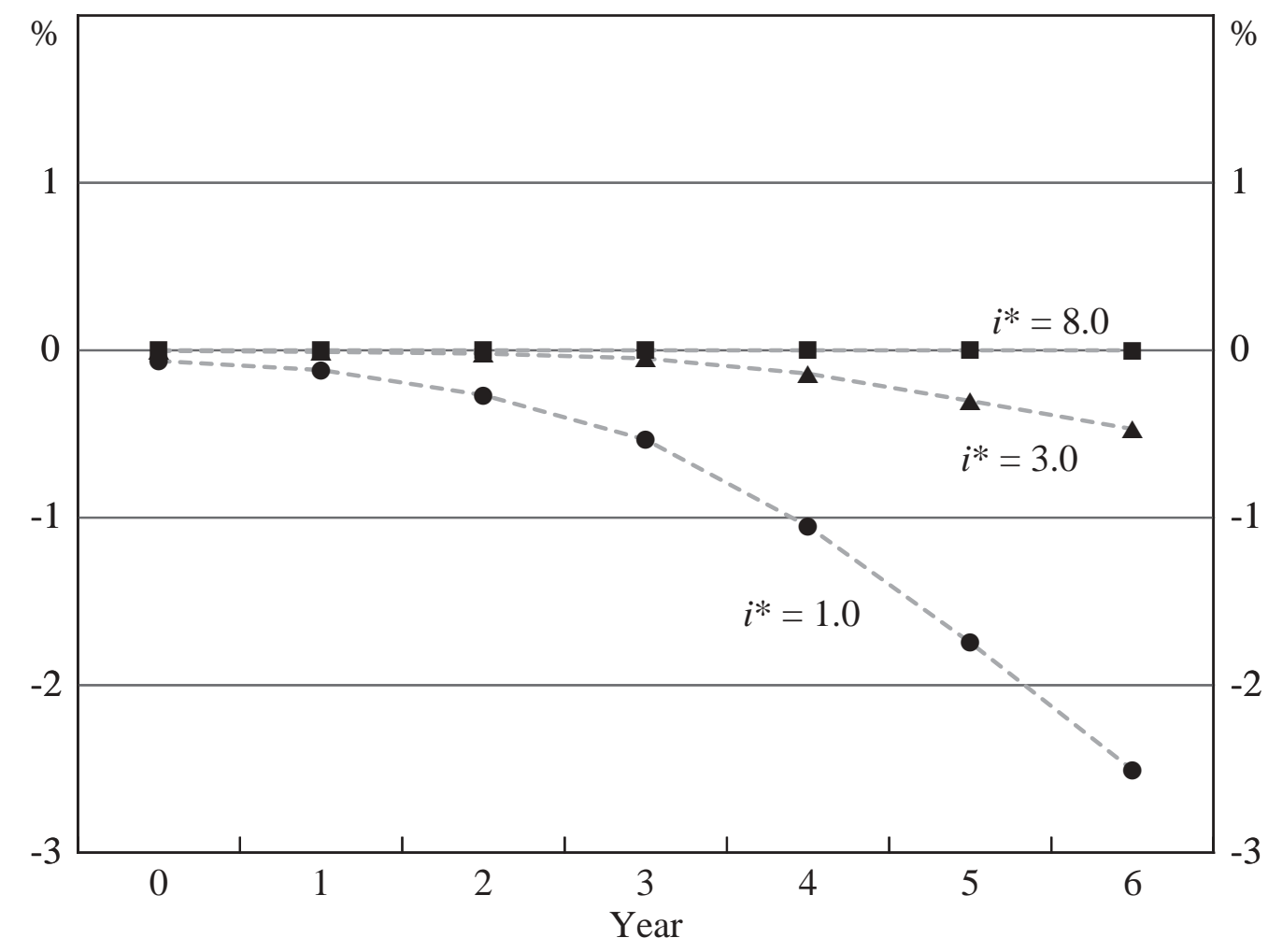

Notes: The sceptic implements policy in each year.

We see that, for our baseline Ball-Svensson model, the compounding effect just described becomes yet more acute if $i^{*}$ is extremely low, so that for $i^{*}=1$ per cent the downward 'ZLB effect' on an activist's recommendations is already noticeable by year 2 , and exceeds 1 percentage point by year 4 . By contrast, this 'ZLB effect' is still negligible, even in year 6 , if $i^{*}$ is set to be 8 per cent, well away from zero. 


\subsection{Bubbles whose Probability of Bursting is Affected by Policy}

Next, instead of a bubble whose growth is affected by policy, consider a bubble whose period-to-period probability of bursting may be influenced by the actions of policy-makers. Specifically, assume that, by setting tighter (looser) policy this year, policy-makers can raise (lower) the probability that the bubble will burst next year, according to the relationship

$$
p_{t}=\frac{1}{1+e^{a\left(r_{t-1}-r_{t-1}^{*}\right)+b}}
$$

where: $r_{t}^{*}, t \geq 0$, denotes the optimal path chosen by a sceptical policy-maker while the bubble survives, assuming a constant period-to-period probability of bursting $p^{*}$ (except $\left.p_{14}=1\right)$; and where $b=\ln \left(\left(1-p^{*}\right) / p^{*}\right)$ and $a=-\delta /\left(p^{*}(1-\right.$ $\left.p^{*}\right)$ ) for some fixed sensitivity parameter $\delta$.

We choose this functional form, which was also used in Gruen et al (2003), for three reasons. First, it ensures that, while raising last year's interest rate, $r_{t-1}$, raises the probability that the bubble will burst this year, $p_{t}$, it cannot drive this probability to one. Secondly, it possesses the property that $p_{t}=p^{*}$ when $r_{t-1}=r_{t-1}^{*}$, the benchmark policy settings chosen by the sceptic. Finally, it has the property that $\partial p_{t} / \partial\left(r_{t-1}-r_{t-1}^{*}\right)=\delta$ when this derivative is evaluated at $r_{t-1}=r_{t-1}^{*}$, so that the parameter $\delta$ gives the marginal sensitivity of the bubble's probability of bursting to changes in the real interest rate, at the sceptic's benchmark policy settings. For the results which follow we adopt the baseline choices $p^{*}=0.4$, consistent with the bulk of our earlier simulations, and $\delta=0.2$, corresponding to a moderate level of interest rate sensitivity.

In this setting, and for an economy with $i^{*}=3$, Figure 7 shows a comparison of the optimal interest rate recommendations of a sceptic and two activists, while the bubble survives. The two activists differ in the way that their actions are influenced by the ZLB: the first is constrained by it, while the second is not.

The most striking feature of Figure 7 is that the impact of the ZLB is no longer in a uniform direction, over time. Up to and including year 4, the effect of the ZLB on an activist policy-maker is to make them recommend tighter policy than otherwise. However, in year 5 this shifts, and the effect of the ZLB becomes such as to cause an activist to recommend looser policy than otherwise, in this and 


\section{Figure 7: Real Interest Rate Recommendations While the Bubble Survives}

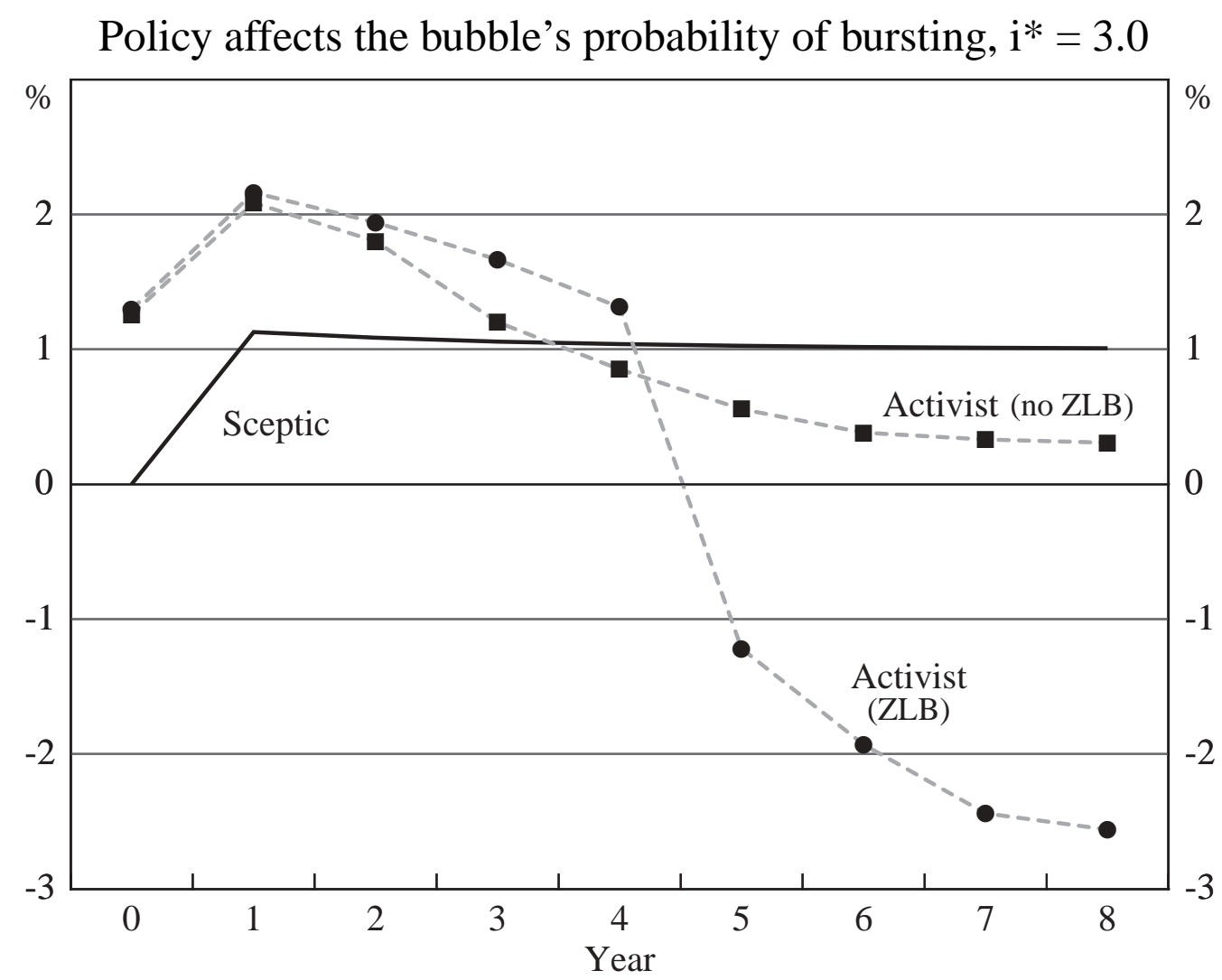

Notes: The sceptic implements policy in each year. Real interest rates are deviations from neutral.

subsequent years. Moreover, this shift is very dramatic, with the 'ZLB effect' on an activist policy-maker moving from positive 46 basis points in year 4 to negative 178 basis points in year 5 .

Once again, we can interpret these results in terms of our 'insurance framework' for analysing the impact of the ZLB, described in Section 3. Recall that, as for bubbles whose growth is affected by policy, in the current setting there are two alternative forms of insurance against encountering the ZLB available to an activist policy-maker. The first is the standard approach of building a buffer of extra inflation and output against the effects of the bubble's eventual collapse, by running policy more loosely than otherwise. The second is to seek to burst the bubble before it can grow further, and so become a bigger threat to economic stability whenever it does collapse, by running policy more tightly than otherwise.

The results in Figure 7 show that, in the current setting, the latter type of insurance must in fact be better value than the former, up to an including 
period 4. However, in year 5 a threshold is crossed. In this year, assuming the bubble does not burst, an activist policy-maker observes the bubble continuing to grow to a size of 5 percentage points, at the same time as the sceptic's policy settings in previous periods have failed to prepare the economy for the bubble's possible future collapse. The combination of these developments sees an activist's expected cost-benefit trade-off shift suddenly from seeking to burst the bubble, by tightening policy, to seeking to cushion the economy against any future bust, by loosening policy. The decisiveness of the swing from one form of insurance to the other is, in part, driven by the fact that, in the current setting, any loosening in current policy increases the chances of the bubble surviving next period and growing further - so increasing the likelihood, in an activist's considerations, that he may have to cope with the collapse of a very large bubble indeed some time down the track. ${ }^{20}$

To see how these findings change as a function of the economy's steady-state neutral nominal interest rate, Figure 8 shows the difference between the policy recommendations of activist policy-makers, with and without a zero lower bound constraint, for $i^{*}=1,3$ and 8 per cent. Here, these activists assume again that policy can affect the bubble's period-to-period probability of bursting according to Equation (17) with $\delta=0.2$.

Interestingly, for the case where $i^{*}$ is extremely low, at 1 per cent, two differences are apparent relative to the case $i^{*}=3$ just discussed. The first is that, even in the early life of the bubble, the 'ZLB effect' is now marginally negative. The second is that the threshold described above, beyond which an activist shifts to recommending sharply looser policy both than they did in the previous period, and than they would do in the absence of the ZLB, is now crossed earlier. On the other hand, we see that for values of $i^{*}$ far from zero, the 'ZLB effect' is once again negligible, even by the time the bubble has been growing for 6 years.

20 The particular form of the function relating the bubble's probability of bursting next period, $p_{t+1}$, to this period's real interest rate deviation from neutral, $r_{t}$, will of course also influence precisely when this decisive shift in an activist's policy approach will occur, as well as the exact magnitude of the swing. 


\section{Figure 8: Impact of the ZLB on an Activist's Recommendations}

Policy affects the bubble's probability of bursting

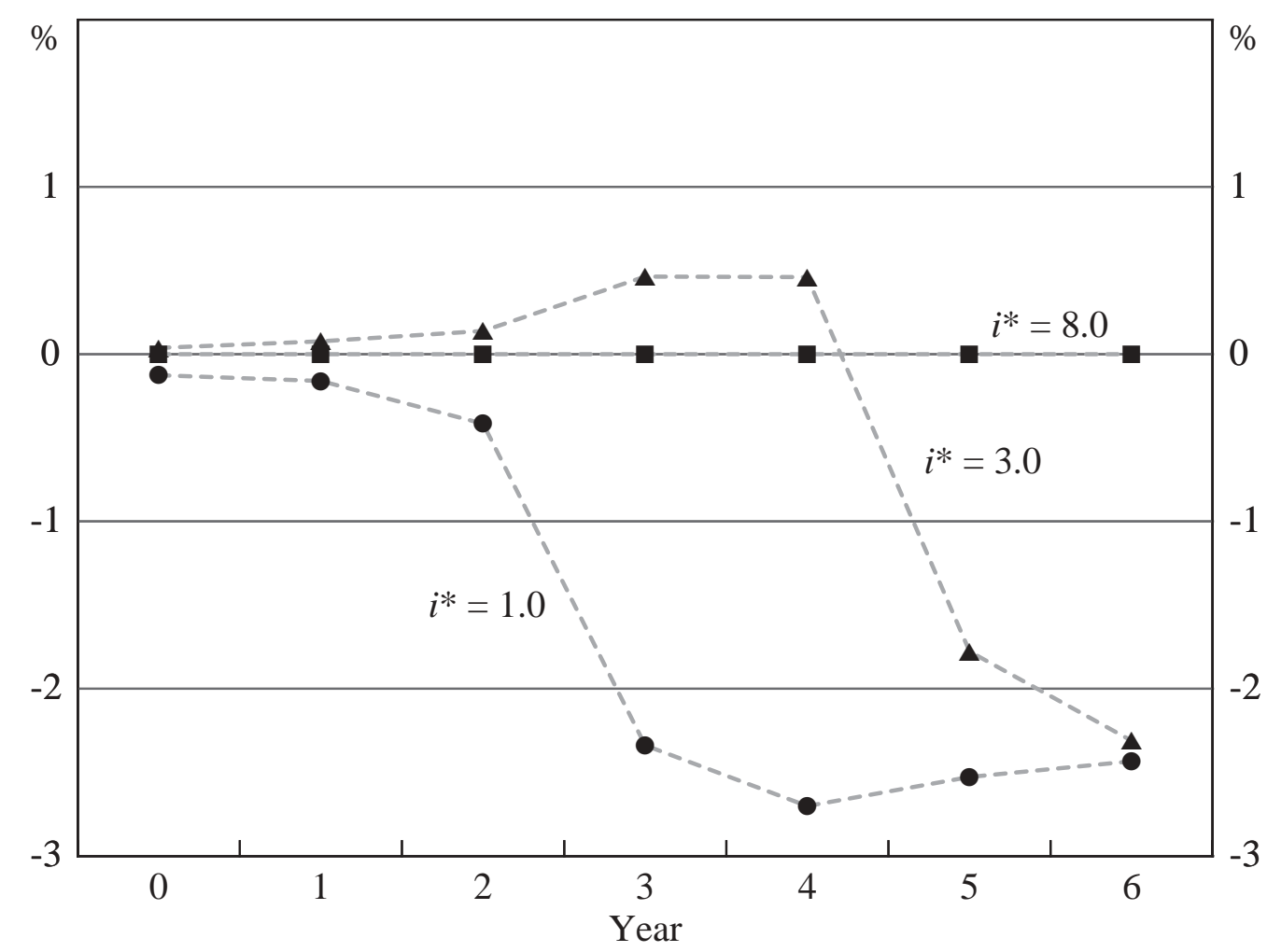

Notes: The sceptic implements policy in each year.

\subsection{Sensitivity to Model Parameters}

It is interesting to explore how sensitive the preceding results are to our choice of model parameters. We focus in particular on the two (positive) parameters $\beta$ and $\lambda$. The former captures how responsive output is to real interest rates. The latter, by contrast, captures how 'naturally self-correcting' our Ball-Svensson economy is, absent any policy action. ${ }^{21}$

Turning first to the case of $\beta$, to assess the sensitivity of an activist's policy recommendations to the value of this parameter we consider again the baseline case of an exogenous bubble with constant period-on-period probability of

21 The smaller is $\lambda$, the more swiftly will output in the economy rebound towards potential, of its own accord, following a shock. Conversely, if $\lambda=1$, the economy has no innate propensity to correct either a positive or negative output gap, once it opens up, so that the full burden of stabilising the economy falls upon policy-makers setting the real interest rate. 
bursting $p_{t}=0.4$ (except $p_{14}=1$ ), and constant growth in the event that it does not burst, $\gamma_{t}=1$. We then consider the recommendations of activists in two different economies, each of which has a steady-state neutral nominal interest rate of 3 per cent, but which differ in their responsiveness to real interest rates - with values of $\beta=0.5$, and 1 respectively. ${ }^{22}$

Figure 9: Impact of the ZLB on an Activist's Recommendations

Sensitivity to alternative values for beta, $i^{*}=3.0$

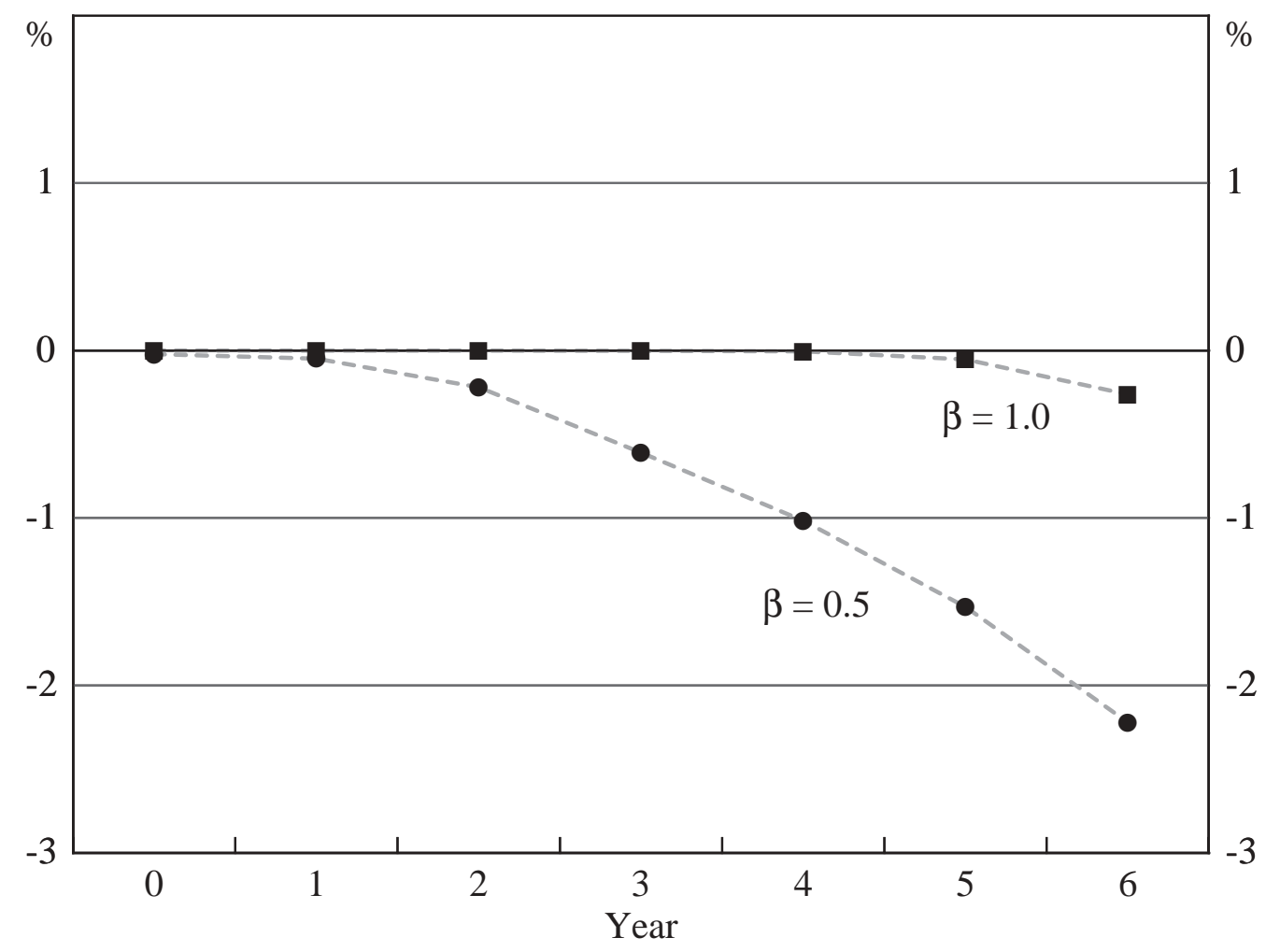

Notes: The sceptic implements policy in each year.

We find that, for an economy with lower responsiveness, the impact of the ZLB on an activist policy-maker's recommendations is correspondingly greater, when faced with an exogenous bubble. This is illustrated in Figure 9, which shows the difference between the policy recommendations of activist policy-makers, with and without a ZLB constraint, in the two economies.

The direction of this result is unsurprising, since the capacity of policy to stabilise the economy following a large negative shock to output is weaker, the smaller is

22 All other model and loss function parameters are assumed to take their baseline values: $\alpha=0.4$, $\lambda=0.8$ and $\mu=1.0$. 
$\beta$. Hence, the activist in our $\beta=0.5$ economy is commensurately more anxious, in each period, to begin building a buffer of added inflation and output against the bubble's eventual collapse, than his counterpart in the $\beta=1$ economy.

What is perhaps surprising is the magnitude of this sensitivity, with the 'ZLB effect' exceeding 1 percentage point as early as period 4 , in the economy with $\beta=0.5$. By contrast, in the $\beta=1$ economy, the corresponding 'ZLB effect' is still negligible in period 4 , and only reaches 26 basis points in period $6 .^{23}$

Correspondingly, to assess the sensitivity of an activist's policy recommendations to the value of $\lambda$, we consider the same baseline case of an exogenous bubble with constant period-on-period probability of bursting $p_{t}=0.4$ (except $p_{14}=1$ ), and constant growth in the event that it does not burst, $\gamma_{t}=1$. Now, however, we consider the recommendations of activists in three different economies, each of which again has a steady-state neutral nominal interest rate of 3 per cent, but which this time differ in the degree to which output is naturally self-correcting in each - with values of $\lambda=0.6,0.8$ and 1 respectively. ${ }^{24}$

In terms of our insurance framework for assessing the likely impact of the ZLB on an activist's recommendations, we would expect this impact to be greatest in the economy with $\lambda=1.0$, and smallest in that with $\lambda=0.6{ }^{25}$ This is indeed what

23 In the $\beta=0.5$ economy the 'ZLB effect' is sufficiently strong that, if the bubble were to survive this long, an activist policy-maker's recommendations would actually reach the zero lower bound by year 7 .

24 Here we revert to the assumption that $\beta=1$ in all three economies, with the parameters $\alpha$ and $\mu$ again at their baseline values of 0.4 and 1 .

25 Policy-makers in the $\lambda=0.6$ economy can expect considerable assistance in restoring output to potential, whenever the bubble bursts, from the economy's natural tendency to rebound from such a shock. By contrast, in the $\lambda=1.0$ economy, policy-makers can expect no such assistance, and so will wish to take out commensurately more insurance against the possible effects of the bubble's future collapse. The same conclusion can be reached more formally in terms of the phase diagram for the Ball-Svensson model discussed in Section 3, and derived in Appendix B. It may readily be checked that, for $0 \leq \lambda \leq 1$, increasing the value of $\lambda$ makes the slopes of both the boundary lines separating Regions I, II and III more negative. Hence, increasing $\lambda$ brings both Regions II and III, which an activist policy-maker wishes to stay away from, closer to the origin in $\left(y_{t}, \pi_{t}\right)$-space - and so increases the incentive for such an activist to recommend looser policy than otherwise, to shift the economy upwards and to the right, away from these danger zones. 
we find, as illustrated in Figure 10, which shows the difference between the policy recommendations of activist policy-makers, with and without a ZLB constraint, in each of our three economies. This time, however, the variation in the impact of the ZLB across our three economies is not substantial, at least until the bubble has grown very large, which suggests that our earlier results are fairly robust to plausible changes in the value of $\lambda .^{26}$

Figure 10: Impact of the ZLB on an Activist's Recommendations

Sensitivity to alternative values for lambda, $\mathrm{i}^{*}=3.0$

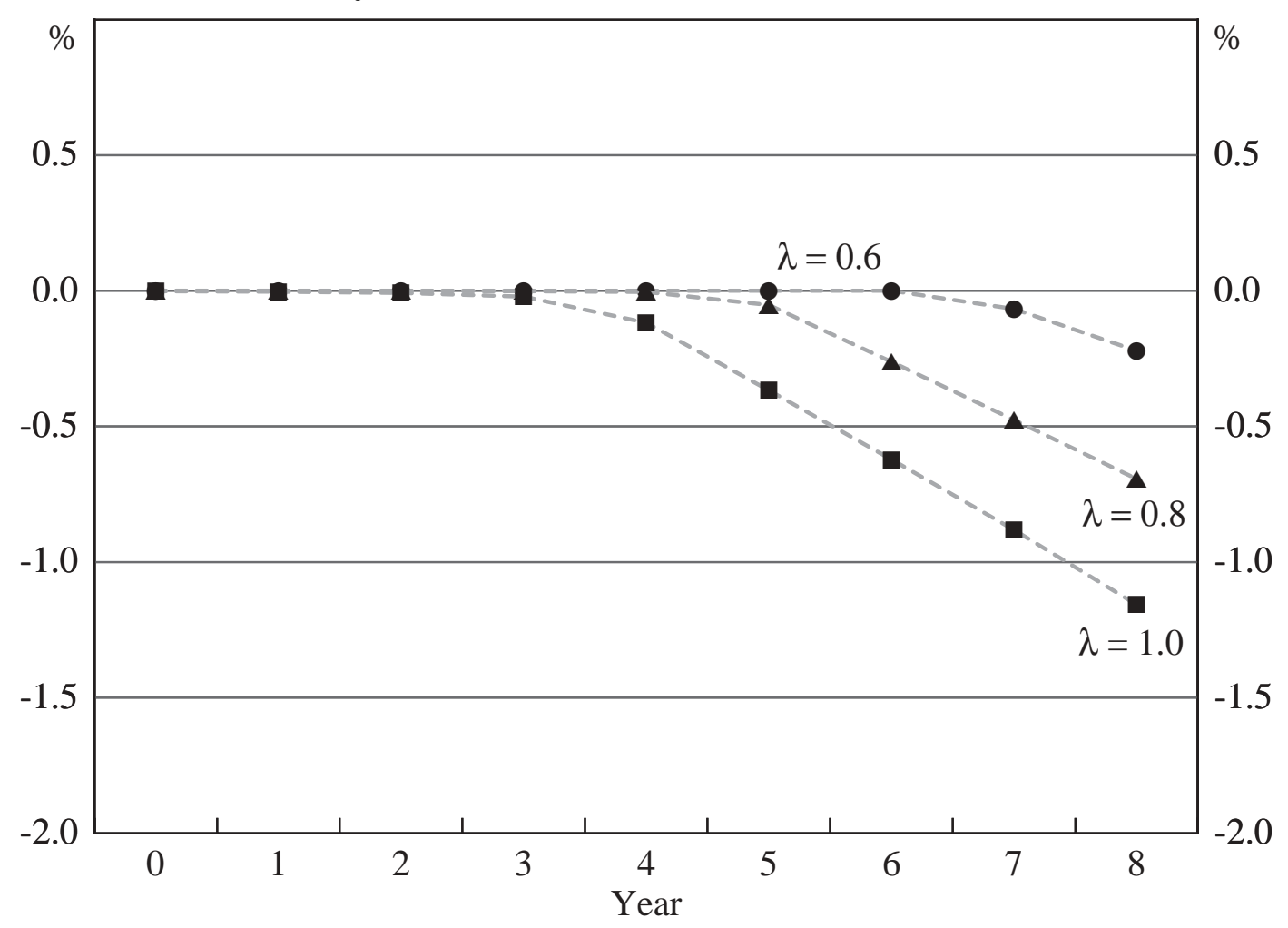

Notes: The sceptic implements policy in each year.

\section{Conclusions}

In this paper we have used a simple, two equation model of a closed economy, augmented with an asset-price bubble, to investigate what impact the zero lower bound on nominal interest rates has on the recommendations of an activist

26 Although we do not show them here, the same point may be seen by directly comparing the successive policy recommendations of activist and sceptical policy-makers in our three economies, while the bubble survives. 
policy-maker, attempting to respond optimally to a given bubble. In assessing our results, it should be remembered that this framework almost certainly magnifies the impact of the ZLB, most notably because it does not allow for other arms of policy (or unconventional monetary policy operations) to help extricate the economy from a situation in which policy has become constrained by the ZLB.

For example, the possibility of encountering the ZLB in the future would clearly hold fewer fears for monetary policy-makers in an economy with sound public finances, than in one burdened with high net public debt and persistent deficits. In the former, policy-makers would be aware that fiscal policy could be called upon, if necessary, to aid in stimulating the economy and forestalling any risk of deflation becoming entrenched. ${ }^{27}$ Likewise, our closed economy setting precludes the use - as advocated for Japan by numerous authors, such as Svensson (2001) and McCallum (2000) - of exchange rate policy as a tool to help rescue an economy suffering from the effects of a severe asset-price bubble collapse.

Notwithstanding these caveats, our framework has the twin advantages of simplicity and transparency, while at the same time realistically capturing the key elements of the interaction between output, inflation and real interest rates. It thus allows us to draw plausible conclusions regarding at least the direction in which the presence of the ZLB would likely influence the recommendations of an activist policy-maker, trying to respond optimally to a bubble. It also allows us to understand intuitively the mechanisms driving these conclusions, and how the relative importance of these mechanisms might vary as we alter either the stochastic properties of the bubble, or the parameters which characterise the economy.

Table 1 summarises the results from our various numerical simulations, for the case of an economy with a steady-state neutral nominal interest rate of $i^{*}=$ 3 per cent. For each scenario the table shows, as time proceeds and the bubble

27 This is not to say that, in an economy with sound public finances, policy-makers would be unconcerned about the possibility of encountering the ZLB, since any requirement for bond-financed fiscal stimulus would result in the accumulation of net debt which must subsequently be repaid (and which might also entail undesirable intergenerational transfers). Rather, it is to say that they would likely assess the costs of encountering the ZLB to be far lower than is implied in our framework. This would be especially so in the 'deflationary trap' region of $\left(y_{t}, \pi_{t}\right)$-space, from much of which it would now be possible to escape with the aid of fiscal stimulus, so avoiding the catastrophic losses associated with a deflationary spiral. 
grows, whether the impact of the ZLB on an activist's recommendations would be to make to make them tighter $(+)$, looser $(-)$ or little different $(=)$ than otherwise (where 'little different' here denotes an impact of less than 25 basis points).

\section{Table 1: Impact of the ZLB on an Activist's Recommendations}

Tighter $(+)$, looser $(-)$, or little different $(=)$ than otherwise, $i^{*}=3.0$

\begin{tabular}{lcccccc}
\hline Scenario & Year 1 & Year 2 & Year 3 & Year 4 & Year 5 & Year 6 \\
\hline Policy can't affect bubble & & & & & & \\
$p_{t}=0.2$, baseline model & $=$ & $=$ & $=$ & - & - & - \\
$p_{t}=0.4$, baseline model & $=$ & $=$ & $=$ & $=$ & $=$ & - \\
$p_{t}=0.4, \beta=0.5$ & $=$ & $=$ & - & - & - & - \\
$p_{t}=0.4, \lambda=0.6$ & $=$ & $=$ & $=$ & $=$ & $=$ & $=$ \\
$p_{t}=0.4, \lambda=1.0$ & $=$ & $=$ & $=$ & $=$ & - & - \\
Policy affects bubble growth & $=$ & $=$ & $=$ & $=$ & - & - \\
Policy affects probability of bursting & & & & & & \\
$p^{*}=0.4, \delta=0.2$ & $=$ & $=$ & + & + & - & - \\
\hline
\end{tabular}

There are two broad sets of lessons worth highlighting from this summary. The first concerns the appropriate level of the steady-state neutral nominal interest rate - the sum of the economy's neutral real interest rate and policy-makers' choice of target inflation rate. From Table 1 we see that, even for a very low neutral nominal interest rate of $i^{*}=3$ per cent, in most scenarios the ZLB has relatively little effect on the thinking of an activist policy-maker until the bubble has become quite large. ${ }^{28}$ Moreover, as Figures 3, 6 and 8 confirm, even those 'ZLB effects' in Table 1 which are not negligible dissipate rapidly as the neutral nominal interest rate is raised above 3 per cent.

These observations suggest that fears of encountering the ZLB should not be overstated, unless the neutral nominal interest rate in the economy is very low. They thus have an obvious implication for policy-makers anxious not to have to worry about factoring the ZLB into their thinking, when trying to cope with an asset-price bubble. Such policy-makers should simply avoid targeting too low an

28 The two exceptions are: when the bubble's probability of bursting may be influenced by policy; and when the bubble is exogenous but the economy is relatively unresponsive to policy-makers' actions. In these two cases the 'ZLB effect' exceeds 25 basis points when the bubble is still only of a moderate size. 
inflation rate, so as to ensure that the economy's neutral nominal interest rate is in turn not too low - say, not below 4 per cent, for our stylised, baseline economy. ${ }^{29}$

The results in Table 1 also shed light on how the ZLB ought optimally to affect the recommendations of an activist policy-maker, facing an asset-price bubble, for a given target inflation rate. We may interpret these results through the 'insurance' framework for analysing the impact of the ZLB on an activist's thinking, described in Section 3.

As discussed there in detail, there are three forms of 'insurance' which a policy-maker can take out against the risk of encountering the ZLB due to the future bursting of an asset-price bubble. Two of these - to attempt to deflate the bubble before it can grow further, or to restrain its future growth - are available only if policy-makers can influence the future behaviour of the bubble. The third, to build a buffer of extra inflation and output against its future collapse, is always available to policy-makers.

The results in Table 1 (together with those shown in Figures 3, 6 and 8) suggest that, for the scenarios we have considered, the third form of insurance is typically the most cost-effective, even where the first two are available. However, this is not uniformly so - and, for different scenarios, which form of insurance is most cost-effective seems to depend delicately upon the parameters describing both the economy and the stochastic properties of the bubble. Indeed, in some instances, such as when policy-makers can influence a bubble's probability of bursting, it appears that the form of insurance which represents the best value for an activist can even switch suddenly and decisively from one period to the next. Overall, therefore, whether the ZLB should cause policy-makers to operate policy more tightly or more loosely than they would otherwise do, while a bubble is growing, would seem to be a subtle question - even after abstracting from the significant informational difficulties facing policy-makers in practice.

29 Hence, for example, a target inflation range with a mid-point of 1 per cent might well be too low for such policy-makers, in our baseline economy, unless the neutral real interest rate in their economy were thought to exceed 3 per cent. 


\section{Appendix A: Recent Literature}

This paper lies at the intersection of two broad areas, both of which have been the subject of extensive research interest in recent years.

The first relates to the issue of how monetary policy should respond to asset price bubbles. Work in this area has focussed on whether policy-makers ought to make allowance for perceived asset price misalignments in setting policy; and, if so, whether such allowance ought to be explicit, through the inclusion of asset prices in either the policy-maker's objective function or policy rule, or merely implicit. ${ }^{30}$ A related issue, which has also received recent attention, is whether success in achieving low and stable inflation may, in fact, increase either the frequency with which asset price misalignments develop, or the severity of such misalignments (Borio and Lowe 2002).

The second broad research area relates to the implications, both for the economy and for monetary policy, of deflation and the zero lower bound on nominal interest rates. An initial wave of interest in these implications was prompted by Japan's experiences with both phenomena, starting around the late 1990s. Since then, such research has gained renewed impetus recently from concerns that some other major economies, such as the US and Germany, might have been flirting with deflation, following significant economic downturns.

Within this second broad area, the literature to date may be roughly divided into two streams. The first of these consists of theoretical analyses of the policy issues raised by deflation and the zero lower bound. These issues include the causes and implications of a liquidity trap, and the role (if any) of foreign exchange or asset market interventions in escaping from such a trap (see, for example, Svensson (2001) and McCallum (2000)). They also encompass the costs and benefits of co-ordinated fiscal and monetary policy actions, such as 'helicopter drops' (Bernanke 2000), or of other more abstract policy options such as Gesell taxes on money balances (Goodfriend 2000), designed to extricate an economy from deflation. Finally, they also include the role (if any) of the choice of monetary policy regime - and in particular the decision whether or not to adopt a

30 For the two opposing views in this debate see Bernanke and Gertler (2001) and Cecchetti, Genberg, Lipsky and Wadhwani (2000). 
price-level or inflation target - in also helping an economy to escape from deflation (Krugman 1998).

The second stream consists of empirical or historical examinations of these same issues. Such examinations have primarily focussed on the experiences of Japan since the early 1990s (see, for example, Posen (2003) and Fukao (2003)), but also include re-examinations of other relevant episodes, such as the attempt by US authorities in the 1960s to increase liquidity, and lower long-term bond rates, through 'Operation Twist' (see Modigliani and Sutch (1966)). ${ }^{31}$

As noted earlier, this paper lies at the overlap between the two broad research areas just described. From this viewpoint, the asset-price bubbles in this paper may be regarded, at one level, as just one particular source of shocks with the potential especially if inflation is being held at too low a level prior to such a shock - to drive the economy to a state where the zero lower bound becomes a constraint on policy. The experiences of Japan in the early 1990s, and of the US more recently, suggest that this is certainly an important area for current research.

There is an important difference, however, between our focus in this paper, and that of the bulk of the literature on deflation and the zero lower bound just described. The greater part of that literature concentrates on the economic implications of the zero lower bound, and on what policy-makers should do to escape from this constraint, once it has been reached. By contrast, our concern in this paper is with the ways in which the existence of the zero lower bound ought to influence policy-makers prior to any negative shock - in our setting, caused by the collapse of a bubble - which might drive the economy into recession and deflation.

31 Of course, the distinction between these two streams is to some extent artificial, since many studies have included both a theoretical and empirical component. 


\section{Appendix B: The Phase Diagram for the Ball-Svensson Model under Optimal Policy}

In this appendix we outline the derivation of the phase diagram (Figure 1) discussed in Section 3 of the main body of the paper. This phase diagram is replicated in Figure A1 below, now for the case of general model and loss function

Figure B1: Phase Diagram for the Ball-Svensson Model under Optimal Policy

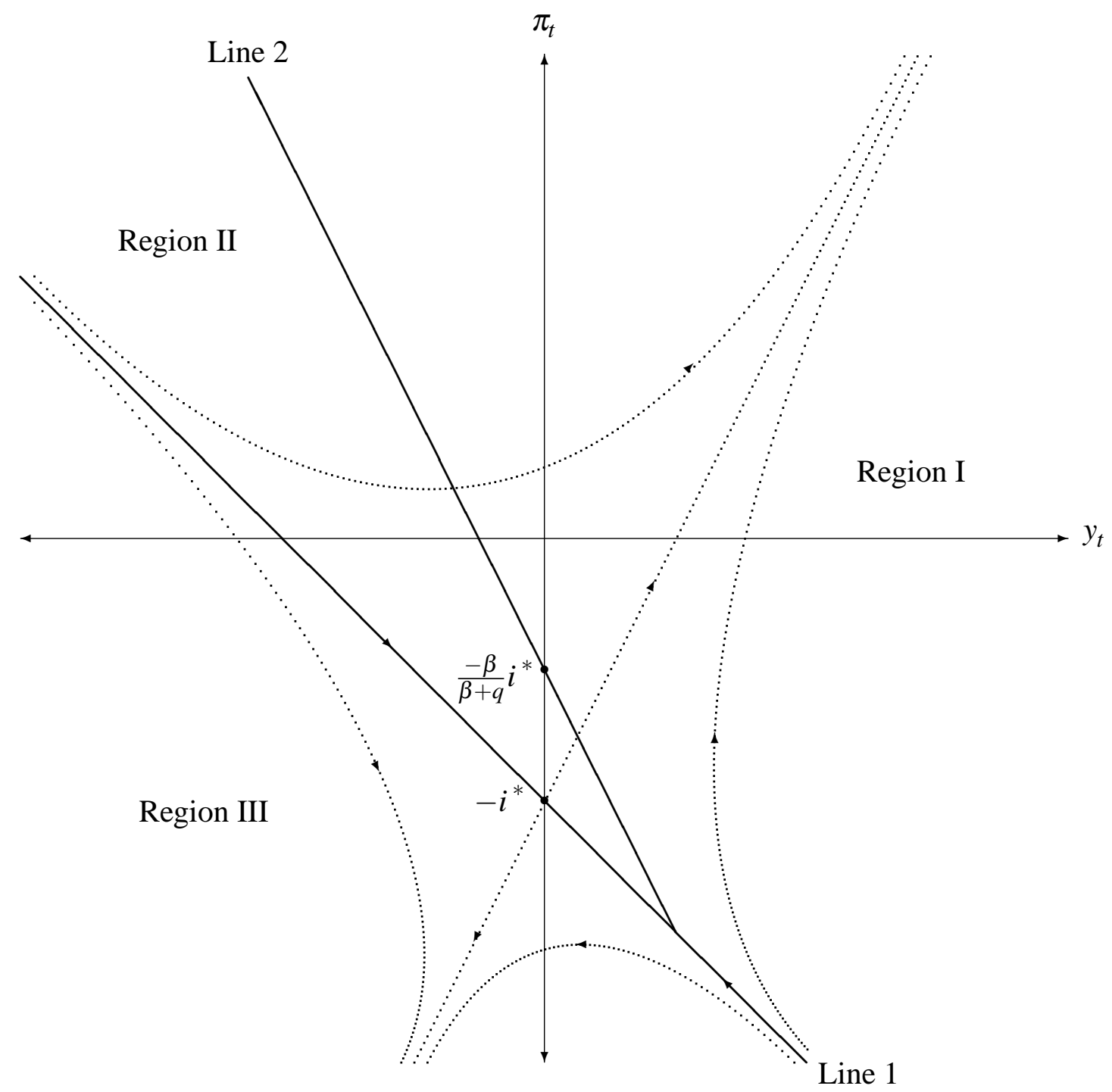

Notes: Dotted lines with arrows denote sample trajectories for the evolution of $\left(y_{t}, \pi_{t}\right)$, absent future shocks to output or inflation, in the event that the nominal interest rate is held at zero. Line 1 passes through the point $\left(0,-i^{*}\right)$ and has slope $\left((1-\lambda)-\left((1-\lambda)^{2}+\right.\right.$ $\left.4 \alpha \beta)^{1 / 2}\right) / 2 \beta$. Line 2 passes through the point $\left(0,-(\beta / \beta+q) i^{*}\right)$ and has slope $-(\lambda+$ $\alpha q) /(\beta+q)$, where $q$ is the scalar defined earlier (see p. 7). 
parameters $\alpha, \beta, \lambda$ and $\mu$. Note that this phase diagram represents a particular case of that derived previously, by Reifschneider and Williams (2000), for the Ball-Svensson model with policy determined by a general Taylor Rule. ${ }^{32}$

The basic idea of this phase diagram is that we can separate $\left(y_{t}, \pi_{t}\right)$-space into three distinct components, as follows:

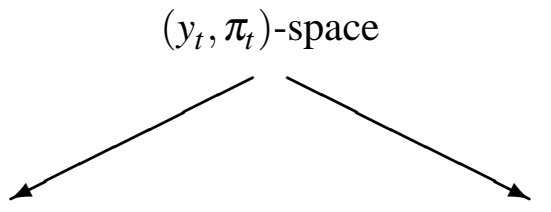

Part in which the economy will enter a deflationary spiral (DS), in the absence of future shocks to output or inflation, even with the nominal interest rate set to zero (Region III)
Part in which the economy will not enter a deflationary spiral (Non-DS), in the absence of future shocks to output or inflation, if the nominal interest rate is set to zero

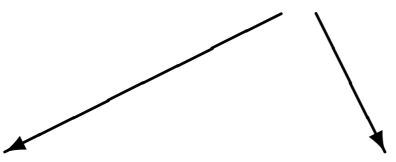

Part of the Non-DS Region in which the zero lower bound will initially be binding, under optimal policy to restore the economy to steady state (Region II)
Part of the Non-DS Region in which, absent future shocks, optimal policy will be able to restore the economy to steady state without ever striking the zero lower bound (Region I)

We begin by establishing the existence and properties of Region III. To this end observe that, in the absence of future shocks to output or inflation, the evolution of our Ball-Svensson economy may be described, in terms of nominal interest rates, by the system

$$
Z_{t}=M Z_{t-1}-\beta X_{t}
$$

where the matrix $\mathrm{M}$, and the vectors $Z_{t}$ and $X_{t}$, are defined by

$$
M \equiv\left(\begin{array}{cc}
\lambda & \beta \\
\alpha & 1
\end{array}\right) \quad, \quad Z_{t} \equiv\left(\begin{array}{c}
y_{t} \\
\pi_{t}
\end{array}\right) \quad, \quad X_{t} \equiv\left(\begin{array}{c}
i_{t-1}^{l v l}-i^{*} \\
0
\end{array}\right)
$$

32 Here we consider only the case where policy is set optimally, which turns out to be a specific instance of a Taylor Rule - see Equation (12). For an alternative discussion of this phase diagram from that provided here, see Reifschneider and Williams (2000). 
Now consider the question: what initial conditions for $Z$ would result in the economy entering a deflationary spiral, even in the event that $i^{l v l}$ were held at the zero lower bound? To answer this question note that, for $i^{l v l}=0$, Equation (B1) may be re-written more simply as

$$
W_{t}=M W_{t-1}
$$

where $W_{t}$ denotes the vector $W_{t}=\left(y_{t}, \pi_{t}+i^{*}\right)^{T}$. Then, for this simplified system, the evolution of any initial $W_{t}$ is clearly determined simply by the eigenvalues, $\xi_{ \pm}$, and eigenvectors, $v_{ \pm}$, of the matrix $M$, which are readily computed to be:

$$
\xi_{ \pm}=\frac{1}{2}\left\{(1+\lambda) \pm\left((1-\lambda)^{2}+4 \alpha \beta\right)^{1 / 2}\right\}
$$

and

$$
v_{ \pm}=\left(\begin{array}{c}
2 \beta \\
(1-\lambda) \pm\left((1-\lambda)^{2}+4 \alpha \beta\right)^{1 / 2}
\end{array}\right) .
$$

Note that, for $\alpha, \beta, \lambda>0$, then $\xi_{+}$will clearly satisfy $\xi_{+}>1$; while $\xi_{-}$will satisfy $0<\xi_{-}<1$ provided $\lambda>\alpha \beta$ (which certainly holds for our baseline choice of model parameters: $\alpha=0.4, \beta=1$ and $\lambda=0.8$ ).

Hence, translating back to $\left(y_{t}, \pi_{t}\right)$-coordinates, we see that $\left(y_{t}, \pi_{t}\right)$-space may be split into two halves, in one of which the economy will enter a deflationary spiral even with nominal interest rates set to zero, as shown in Figure A1. The line separating these two halves passes through the point $\left(0,-i^{*}\right)$, and has slope equal to that of the eigenvector $v_{-}$, namely $\left((1-\lambda)-\left((1-\lambda)^{2}+4 \alpha \beta\right)^{1 / 2}\right) / 2 \beta$. This slope is approximately -0.54 for our baseline choice of model parameters.

In addition, the non-deflationary-spiral component of $\left(y_{t}, \pi_{t}\right)$-space may itself be subdivided into two parts: one where the zero lower bound will initially be binding on optimal policy (Region II); and one (Region I) where it will not be binding (so that, absent future shocks, the economy may be returned to steady-state without ever setting nominal interest rates to zero).

The dividing line between these two regions will simply be given by the set of states $\left(y_{t}, \pi_{t}\right)$ for which the associated unconstrained optimal nominal interest rate recommendation exactly equals zero. Yet we know that, for any given levels 
of the output gap and inflation, the unconstrained optimal real interest rate recommendation is simply

$$
r_{t}^{l v l}=r^{*}+\beta^{-1}(\lambda+\alpha q) y_{t}+\beta^{-1} q \pi_{t}
$$

where the scalar $q$ is defined by $q=\left(-\mu \alpha+\left(\mu^{2} \alpha^{2}+4 \mu\right)^{1 / 2}\right) / 2$. Hence, since $i_{t}^{l v l}=r_{t}^{l v l}+\pi_{t}+\pi^{*}$, the dividing line between Regions I and II will be precisely the line

$$
i^{*}+\beta^{-1}(\lambda+\alpha q) y_{t}+\beta^{-1}(\beta+q) \pi_{t}=0
$$

or, in other words,

$$
\pi_{t}=-\frac{\beta}{\beta+q} i^{*}-\frac{\lambda+\alpha q}{\beta+q} y_{t} .
$$

Note that this passes through the point $\left(0,-(\beta / \beta+q) i^{*}\right)$ and has slope $-(\lambda+$ $\alpha q) /(\beta+q)$, as shown in Figure A1.

This completes the derivation, for general model and loss function parameters, of the phase diagram for the Ball-Svensson model under optimal policy. ${ }^{33}$

33 While we do not pursue this further here, it is also possible to use this phase diagram (Figure B1) to better understand the precise way in which being in Region II will result in additional loss for a policy-maker, over and above that which they would expect to incur in the absence of the ZLB. The key observation is that, without the ZLB, our Ball-Svensson economy will evolve under optimal policy according to the equation $Z_{t}=U Z_{t-1}$ where $U$ is a $2 \times 2$ matrix with eigenvalues 0 and $(1-\alpha q)$. Computation of the corresponding eigenvectors, which turn out to be $(1-\alpha)^{T}$ and $(q-1)^{T}$ respectively, allows the way in which optimal policy moves the economy around in $\left(y_{t}, \pi_{t}\right)$-space to be easily pictured - and hence, in turn, allows the impact of the ZLB on a policy-maker, trying to stabilise an economy in Region II, to be understood geometrically in terms of the phase diagram. 


\section{Appendix C: The Case of Rational Bubbles}

For the baseline results presented in Section 4.1, the asset-price bubble considered there grew at a uniform rate, $\gamma_{t}=1$, and had a probability of collapse which was constant through time. However, under certain assumptions about the relationship between the price growth underlying an asset bubble and the impact of that bubble on the real economy, such a bubble could be regarded as irrational: that is, in violation of an arbitrage condition ruling out unexploited profit opportunities in the assets whose price rises constitute the bubble. ${ }^{34}$

As in Gruen et al (2003), we do not see this as a shortcoming per se, since there is much evidence in developed economies of irrational bubbles occurring in practice - see, for example, Shiller (2000). Nevertheless, it is interesting to consider whether the imposition of a rationality assumption on our bubbles would affect our overall findings and, if so, how.

To address this question we must first quantify what it means for a bubble to be rational. Such a bubble arises from the actions of a rational investor who buys the relevant assets up to the point at which expected profits are driven to zero. ${ }^{35}$ If the probability of collapse is constant, $p^{*}$, and the capital gain to the investor in year $t+1$ if the bubble collapses is $-a_{t}$, then a rational risk-neutral investor will be indifferent to holding the asset when the expected growth of the bubble, if it survives, is $\Delta a_{t+1}=a_{t} p^{*} /\left(1-p^{*}\right)$. This is a geometrically growing bubble, rather than the constant-growth bubble that constituted our baseline case. ${ }^{36}$

34 The required assumptions are that the effect on the output gap of a change in asset prices is proportional to the size of the change, and that rational investors and the activist policymaker agree on the exact stochastic details of the bubble. We adopt these two assumptions throughout the remainder of this appendix.

35 We assume that the assets yield an annual return equal to the real interest rate, so that the expected profit relative to holding one-year government bonds is determined by the expected capital gain on the assets.

36 This geometric growth formula for $\Delta a_{t+1}$ is simply another way of stating the arbitrage condition that defines a rational bubble, namely that the bubble's expected growth over the next year, $E_{t} \Delta a_{t+1}$, should be zero. Note also that, if the probability of collapse is not constant, a rational bubble need not grow at a constant geometrical rate. 
Having quantified the condition for an exogenous bubble to be rational, we are now in a position to examine whether the imposition of a rationality assumption on our bubbles would fundamentally alter our earlier findings as to the impact of the ZLB on the recommendations of an activist policy-maker. To this end, Figure $\mathrm{C} 1$ shows the difference between the recommendations of activist policy-makers, with and without a ZLB constraint, for the case of a rational bubble with size 1 in period 0 , and with constant probability of bursting $p^{*}=0.2 .^{37}$ Results are shown for the three cases $i^{*}=1,3$ and 8 per cent.

\section{Figure C1: Impact of the ZLB on an Activist's Recommendations}

Difference between recommendations with and without the ZLB

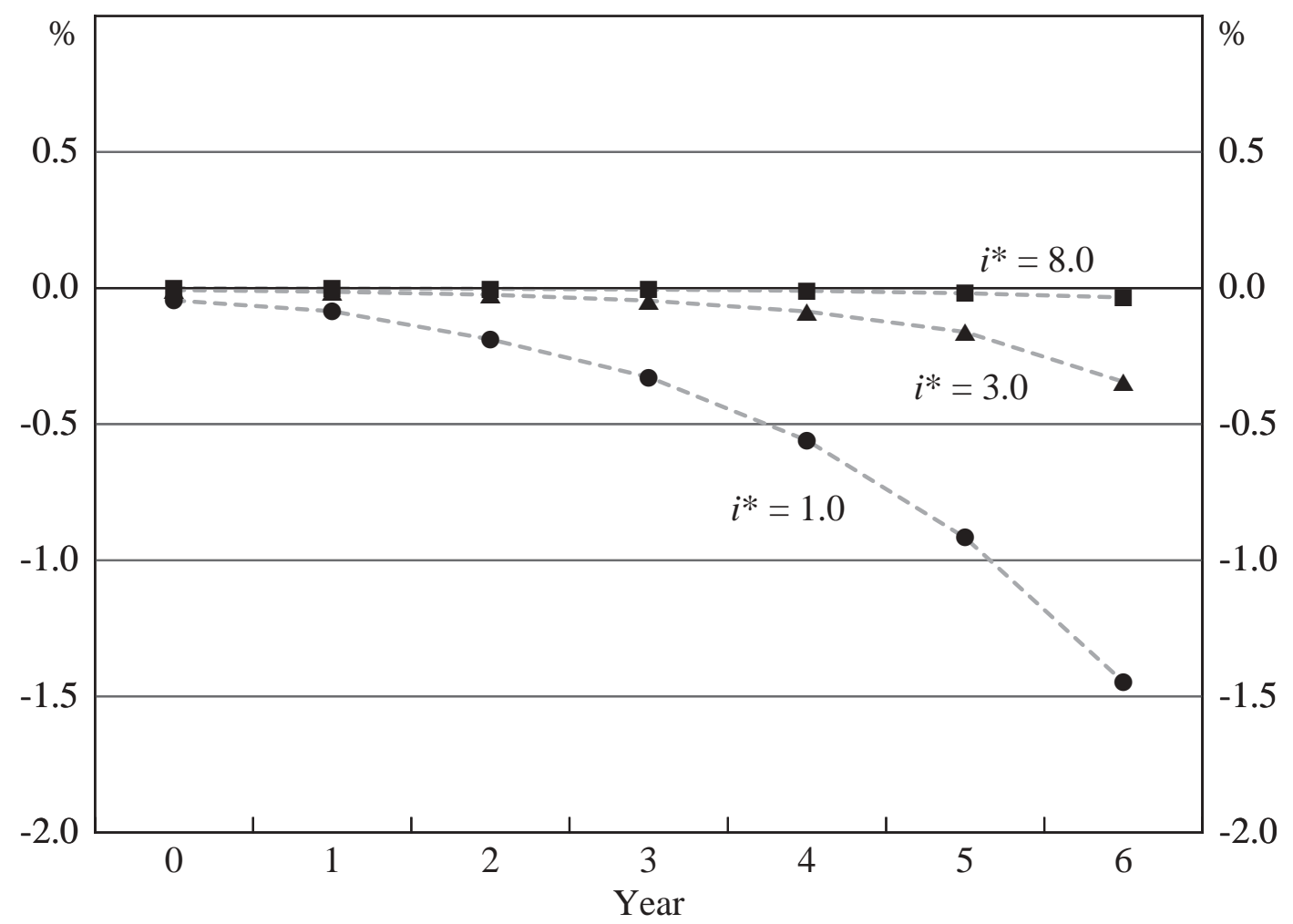

Notes: The sceptic implements policy in each year.

37 The assumption that the bubble has size 1 in period 0 (with $y_{0}$ also assumed equal to 1 , consistent with the scenario that the bubble has spontaneously developed in period 0 , thereby perturbing the economy from the equilibrium state it occupied in the preceding period) is made so as to allow the rational bubble to 'get started'. Since the rationality condition $\Delta a_{t+1}=$ $a_{t} p^{*} /\left(1-p^{*}\right)$ may equivalently be written as $a_{t+1}=a_{t} /\left(1-p^{*}\right)$, we see that without such an assumption a rational bubble would never be able to develop in the first place. 
Strikingly, we see that the results in Figure $\mathrm{C} 1$ for this rational bubble are extremely similar to those shown earlier in Figure 3, for our (irrational) baseline scenario. ${ }^{38}$ This strongly suggests that the general thrust of our various findings in Section 4, regarding the impact of the ZLB on the recommendations of an activist policy-maker, is unlikely to be sensitive to the imposition of a rationality constraint on the bubbles considered there. ${ }^{39}$

38 The extreme closeness of this similarity is to some extent coincidental, since the constant period-to-period probability of bursting is different for the two bubbles: $p^{*}=0.4$ for the baseline bubble considered in Figure 3, versus $p^{*}=0.2$ for the rational bubble considered in Figure $\mathrm{C} 1$ above. Were we to assume also $p^{*}=0.4$ for the rational bubble, the growth of this bubble would accelerate so much more quickly, while it survived, than in the $p^{*}=0.2$ case, that the downward impact of the ZLB on an activist's policy recommendations would be evident both much earlier and more strongly than in Figure $\mathrm{C} 1$. The important point, however, is that the general nature of this impact - namely to push down the optimal recommendations of an activist, and to do so increasingly strongly over time - would be unchanged.

39 This is not to say that, for an activist policy-maker, the recommendations themselves (whether subject to a ZLB constraint or not) would be similar for the two different bubbles just compared: the baseline bubble in Section 4.1 and the rational bubble specified above. Indeed, the results in Section 3 of Gruen et al (2003) show that these recommendations would, in fact, be quite different. Rather, it merely says that, in terms of the marginal impact which the ZLB would have on the optimal recommendations of an activist policy-maker, the general nature of this impact is similar for both types of bubble. 


\section{References}

Ball L (1994), 'What Determines the Sacrifice Ratio?', in NG Mankiw (ed), Monetary Policy, National Bureau of Economic Research Studies in Business Cycles, University of Chicago Press, Chicago, pp 155-182.

Ball L (1999a), 'Efficient Rules for Monetary Policy', International Finance, pp 63-83.

Ball L (1999b), 'Policy Rules for Open Economies', in JB Taylor (ed), Monetary Policy Rules, A National Bureau of Economic Research Conference Report, University of Chicago Press, Chicago, pp 127-144.

Bernanke BS (2000), 'Japanese Monetary Policy: A Case of Self-Induced Paralysis?', in R Mikitani and AS Posen (eds), Japan's Financial Crisis and its parallels to U.S. Experience, Institute for International Economics, Washington.

Bernanke BS and M Gertler (2001), 'Should Central Banks Respond to Movements in Asset Prices?', American Economic Review, 91(2), pp 253-257.

Borio $\mathbf{C}$ and $\mathbf{P}$ Lowe (2002), 'Asset Prices, Financial and Monetary Stability: Exploring the Nexus', Bank for International Settlements Working Paper No 114.

Cecchetti SG (2003), 'What the FOMC Says and Does When the Stock Market Booms', in T Richards and T Robinson (eds), Asset Prices and Monetary Policy, Proceedings of a Conference, Reserve Bank of Australia, Sydney, pp 27-96.

Cecchetti SG, H Genberg, J Lipsky and S Wadhwani (2000), 'Asset prices and central bank policy', International Centre for Monetary and Banking Studies and Centre for Economic Policy Research Geneva Reports on the World Economy No 2.

DeLong BJ and LH Summers (1988), 'How Does Macroeconomic Policy Affect Ouput?', Brookings Papers on Activity, pp 433-480.

Fukao M (2003), 'Financial Strains and the Zero Lower Bound: the Japanese Experience', Bank for International Settlements Working Paper No 141.

Goodfriend M (2000), 'Overcoming the Zero Bound on Interest Policy', Journal of Money, Credit and Banking, 32(4), pp 1007-1035. 
Gruen D, M Plumb and A Stone (2003), 'How Should Monetary Policy Respond to Asset-price Bubbles?', Reserve Bank of Australia Research Discussion Paper No 2003-11.

Krugman PR (1998), 'It's Baaack! Japan's Slump and the Return of the Liquidity Trap', Brookings Papers on Economic Activity, 49(2), pp 137-206.

McCallum BT (2000), 'Theoretical Analysis Regarding a Zero Lower Bound on Nominal Interest Rates', Journal of Money, Credit and Banking, 32(4), pp 870-904.

Modigliani F and R Sutch (1966), 'Innovations in Interest Rate Policy', American Economic Review, LVI, pp 178-197.

Posen AS (2003), 'It Take More Than a Bubble to Become Japan', in A Richards and T Robinson (eds), Asset Prices and Monetary Policy, Proceedings of a Conference, Reserve Bank of Australia, Sydney, pp 203-249.

Reifschneider D and JC Williams (2000), 'Three Lessons for Monetary Policy in a Low-inflation Era', The Journal of Money, Credit and Banking, 32(4), pp 936-966.

Rudebusch GD (1995), 'What are the Lags in Monetary Policy', FRBSF Weekly Letter, pp 95-105.

Shiller RJ (2000), Irrational Exuberance, Princeton University Press.

Svensson LEO (1997), 'Inflation Forecast Targeting: Implementing and Monitoring Inflation Targets', European Economic Review, 41(6), pp 1111-1146.

Svensson LEO (2001), 'The Zero Bound in an Open Economy: A Foolproof Way of Escaping from a Liquidity Trap', Monetary and Economic Studies, 19(S-1), pp 277-312.

Taylor JB (1993), 'Discretion versus Policy Rules in Practice', CarnegieRochester Conference Series on Public Policy, 39, pp 195-214. 